\title{
GluN2B-Containing NMDA Receptors Regulate AMPA Receptor Traffic through Anchoring of the Synaptic Proteasome
}

\author{
Joana S. Ferreira, ${ }^{1,2}$ Jeannette Schmidt, ${ }^{1,3 *}$ Pedro Rio, ${ }^{1,2 *}$ Rodolfo Águas, ${ }^{1}$ Amanda Rooyakkers, ${ }^{4}$ Ka Wan Li, ${ }^{5}$ \\ August B. Smit, ${ }^{5}$ Ann Marie Craig, ${ }^{4}$ and ${ }^{\circ}$ Ana Luisa Carvalho ${ }^{1,2}$ \\ ${ }^{1}$ Center for Neuroscience and Cell Biology, University of Coimbra, 3004-504 Coimbra, Portugal, ${ }^{2}$ Department of Life Sciences, University of Coimbra, \\ 3004-517 Coimbra, Portugal, ${ }^{3}$ Doctoral Program in Experimental Biology and Biomedicine, Center for Neuroscience and Cell Biology and Institute for \\ Interdisciplinary Research, University of Coimbra, 3004-504 Coimbra, Portugal, ${ }^{4}$ Brain Research Centre and Department of Psychiatry, University of British \\ Columbia, Vancouver V6T 2B5, Canada, and ${ }^{5}$ Center for Neurogenomics and Cognitive Research, Neuroscience Campus Amsterdam, VU University, \\ Delaware Boelelaan 1085, 1081 HV, Amsterdam, The Netherlands
}

\begin{abstract}
NMDA receptors play a central role in shaping the strength of synaptic connections throughout development and in mediating synaptic plasticity mechanisms that underlie some forms of learning and memory formation in the CNS. In the hippocampus and the neocortex, GluN1 is combined primarily with GluN2A and GluN2B, which are differentially expressed during development and confer distinct molecular and physiological properties to NMDA receptors. The contribution of each subunit to the synaptic traffic of NMDA receptors and therefore to their role during development and in synaptic plasticity is still controversial. We report a critical role for the GluN2B subunit in regulating NMDA receptor synaptic targeting. In the absence of GluN2B, the synaptic levels of AMPA receptors are increased and accompanied by decreased constitutive endocytosis of GluA1-AMPA receptor. We used quantitative proteomic analysis to identify changes in the composition of postsynaptic densities from GluN2B ${ }^{-1-}$ mouse primary neuronal cultures and found altered levels of several ubiquitin proteasome system components, in particular decreased levels of proteasome subunits. Enhancing the proteasome activity with a novel proteasome activator restored the synaptic levels of AMPA receptors in GluN2B ${ }^{-1-}$ neurons and their endocytosis, revealing that GluN2B-mediated anchoring of the synaptic proteasome is responsible for fine tuning AMPA receptor synaptic levels under basal conditions.
\end{abstract}

Key words: AMPA receptors; GluN2B; iTRAQ; NMDA receptors; postsynaptic density; proteasome

\section{Introduction}

A majority of synapses in the brain function through glutamatemediated activation of NMDA and AMPA receptors. During development, activity-dependent mechanisms adjust the number and strength of synapses, with synapse maturation being accom-

Received Aug. 22, 2014; revised April 22, 2015; accepted April 23, 2015.

Author contributions: K.W.L., A.B.S., A.M.C., and A.L.C. designed research; J.S.F., J.S., P.R., R.Á., A.R., K.W.L., and A.L.C. performed research; A.M.C. contributed unpublished reagents/analytic tools; J.S.F., J.S., K.W.L., A.M.C., and A.L.C. analyzed data; J.S.F. and A.L.C. wrote the paper.

This work was supported by Fundação para a Ciência e a Tecnologia (FCT) and Fundo Europeu De Desenvolvimento Regional-Portugal (Grants PEst-C/LA0001/2013-2014,PTDC/SAU-NEU/099440/2008 and PTDC/NEU-NCM/ 0750/2012), and the Canadian Institutes of Health Research (Grant MOP-96096). J.S.F. was supported by the FCT and Programa Operacional Potencial Humano/Fundo Social Europeu-Portugal (Grants SFRH/BPD/90045/2012 and SFRH/BD/3752/2007). We thank Daniel Finley (Harvard Medical School) for the kind gift of IU1-47; Andrew Irving (University of Dundee) for the GluA1 N-terminus antibody; Richard L. Huganir (Johns Hopkins University) for the anti-phospho-GluA1 T840 antibody; S.D. Santos, M. Vieira, and E. Carvalho for cell culture and genotyping assistance; the Microscopy Imaging Center of Coimbra for technical support; and Laurent Groc (Interdisciplinary Institute for Neuroscience, University of Bordeaux) for helpful discussions on the project and the manuscript.

The authors declare no competing financial interests.

*J.S. and P.R. contributed equally to this work.

Correspondence should be addressed to Ana Luisa Carvalho, CNC-Center for Neuroscience and Cell Biology, University of Coimbra, 3004-504 Coimbra, Portugal. E-mail: al@@nc.uc.pt.

DOI:10.1523/JNEUROSCI.3567-14.2015

Copyright $\odot 2015$ the authors $\quad 0270-6474 / 15 / 358462-18 \$ 15.00 / 0$ panied by an increase in the ratio of AMPA receptor (AMPAR)mediated to NMDA receptor (NMDAR)-mediated currents. The bidirectional regulation of these receptors is an important contributor to the mechanisms of synaptic plasticity thought to underlie learning and memory formation (Santos et al., 2009; Anggono and Huganir, 2012).

NMDARs have particular features as detectors of coincident presynaptic and postsynaptic activity (Mayer et al., 1984). They are formed by two obligatory glycine-binding GluN1 subunits that oligomerize with two glutamate-binding GluN2 subunits or, more uncommonly, with GluN3 subunits (Monyer et al., 1992; Furukawa and Gouaux, 2003; Furukawa et al., 2005; Ulbrich and Isacoff, 2008). The presence of different GluN2 subunits confers different characteristics to the NMDARs: GluN2B-containing receptors have higher calcium permeability; lower open probability and peak current; and slower deactivation, rise, and decay times than GluN2A-contaning NMDARs (Paoletti et al., 2013). These GluN2 subunits are the most abundantly expressed in the forebrain and in the hippocampus CA1 region and their expression is developmentally and regionally regulated (Watanabe et al., 1992; Akazawa et al., 1994; Monyer et al., 1994). Although GluN2B is highly expressed early in development, GluN2A expression starts 
only after birth, exceeding by adulthood GluN2B levels (Sheng et al., 1994). The switch between GluN2B- and GluN2A-containing NMDARs is thought to be regulated by experience and activity (Quinlan et al., 1999; Bellone and Nicoll, 2007) and to contribute to alter the threshold for synaptic plasticity (Yashiro and Philpot, 2008).

The differential role of GluN2A and GluN2B is still one of the most debated issues in neuroscience. Studies addressing the specific role of GluN2B have provided compelling evidence for its essential role in regulating the synaptic accumulation of NMDARs (Hall et al., 2007; von Engelhardt et al., 2008; Akashi et al., 2009; Brigman et al., 2010; Gray et al., 2011; Wang et al., 2011). Recent studies suggest that NMDAR-mediated activity decreases AMPAR-mediated synaptic currents in developing synapses (Hall et al., 2007; Ultanir et al., 2007; Adesnik et al., 2008; Hall and Ghosh, 2008), but the mechanisms underlying this inhibitory pathway are unknown.

Here, we used neuronal cultures from GluN2A ${ }^{-1-}$ and GluN2B $^{-1-}$ mice to discriminate the contribution of these subunits for NMDAR synaptic targeting. We observed a dramatic decrease in the synaptic content of NMDARs in hippocampal neurons from GluN2B ${ }^{-1-}$ mice, accompanied by an increase in the levels of synaptic AMPARs and a decrease of their endocytosis. Using quantitative proteomic methods, we found decreased synaptic levels for proteasome subunits in the postsynaptic densities (PSDs) from GluN2B ${ }^{-1-}$ neurons compared with control neurons. By rescuing proteasome activity using a proteasome activator, we recovered AMPAR endocytosis and synaptic levels of AMPARs in GluN2B ${ }^{-1-}$ neurons to levels similar to wild-type neurons. These results suggest that GluN2B-containing NMDAR-mediated anchoring of the synaptic proteasome is involved in negatively regulating synaptic AMPAR expression during development.

\section{Materials and Methods}

Antibodies. Primary: anti-GluN1 (1:500 WB, \#MAB363), anti-GluN2A (1:1000, \#AB1555P), anti-GluA1 (1:1000 WB or 1:100 ICC, \#AB1504), anti-GluA2 (1:1000 WB or 1:500 ICC, \#MAB397), anti-phospho-GluA1 Ser845 (1:1000, \#AB5849), anti-phospho-GluA2 Ser880 (1:1000, \#07294), phospho-stargazin (Ser239/240) (1:500, \#ab3713), phosphoCaMKII $\alpha / \beta$ subunit (Thr286/287) (1:1000, \#06-881) were from Millipore; anti-GluN1 (1:1500 ICC, \#MAb 54.1) was from Invitrogen; N-terminal of GluA1 (1:50) was a kind gift from Dr. Andrew Irving; anti-PSD-95 (D27E11) (1:2000 WB or 1:100 ICC, \#3450) and antiphospho-protein kinase C (PKC) substrates $(1: 1000$, \#2261S) were from Cell Signaling Technology; anti-SynGAP (1:1000, \#PA1-046) and antiPSD-95 (1:500, \#MA 1.046 C7E3-1B8) were from Affinity Bioreagents; anti-Synaptophysin (1:10000, \#101 011) was from Synaptic Systems; anti-CaMKII $\beta$ (K-19) (1:500, \#sc-100366) was from Tebu-Bio, Santa Cruz Biotechnology); CaMKII $\alpha$ (6G9) (1:2000, \#C265) was from SigmaAldrich; anti-phospho-GluA1 Ser 831 (1:5000, \#2041) was from Tocris Bioscience; anti-phospho-GluA1 T840 was a kind gift from R. Huganir (JH2811); anti-Transferrin receptor antibody (1:1000, \#13-6800) was from Invitrogen; anti-vesicular glutamate transporter 1 (VGLUT1; 1:5000, \#AB5905) was from Millipore; anti-MAP2 (1:5000, \#ab5392) was from Abcam; and anti- $\beta$-actin (1:5000, \#1378996) was from Roche Molecular Biochemicals. Secondary: alkaline phosphatase-affinipure goat anti-mouse IgG (H+L) (1:20000, \# 115-055-062) and alkaline phosphatase-affinipure mouse anti-rabbit $\operatorname{IgG}(\mathrm{H}+\mathrm{L})$ (1:20000, \#211055-109) were from Jackson ImmunoResearch; Alexa Fluor 568 donkey anti-mouse IgG (1:500, \#A10037), Alexa Fluor 488 goat anti-rabbit IgG $(\mathrm{H}+\mathrm{L})(1: 500$, \#A-11008), Alexa Fluor 568 goat anti-mouse $\operatorname{IgG}(\mathrm{H}+\mathrm{L})$ (1:500, \#A11004), Alexa Fluor 647 goat anti-guinea pig $\operatorname{IgG}(1: 500$, \#A21450), Alexa Fluor 488 donkey anti-sheep $\operatorname{IgG}(\mathrm{H}+\mathrm{L})(1: 150$, \#A11015), and Alexa Fluor 568 donkey anti-sheep IgG (1:500,
\#A21099) were from Invitrogen; and anti-chicken-AMCA (1:200, \#103-155-155) was from Jackson ImmunoResearch.

Genotyping. GluN2B ${ }^{+/-}$mice (Kutsuwada et al., 1996) were maintained as described previously (Liu et al., 2007). Genotyping of pups and embryos was performed according to a previously described protocol (Tovar et al., 2000). Briefly, DNA was extracted with phenol/choloroform/isoamyl alcohol (Sigma-Aldrich, \#P3803) after tissue digestion with proteinase $\mathrm{K}(0.1 \mathrm{mg} / \mathrm{ml}$; Invitrogen, \#25530-049). PCR amplification using the Supreme NZYTaq $2 \times$ Green Master Mix (Nzytech, \#MB05402) was performed with specific primers for GluN2B (5' ATG AAG CCC AGC GCA GAG TG 3' and 5' AGG ACT CAT CCT TAT CTG CCA TTA TCA TAG $3^{\prime}$ ) and GluN2A (5' TCT GGG GCC TGG TCT TCA ACA ATT CTG TGC $3^{\prime}$ and 5' CCC GTT AGC CCG TTG AGT CAC CCC T $3^{\prime}$ ) and for the respective neomycin cassette [5' GGC TAC CTG CCC ATT CGA CCA CCA AGC GAA AC $3^{\prime}$ for GluN2B ${ }^{-1-}$ and 5' GCC TGC TTG CCG AAT ATC ATG GTG GAA AAT 3' for GluN2A ${ }^{-1-}$ ]. Because GluN2B ${ }^{-1-}$ mice die shortly after birth, heterozygous mice were mated to obtain GluN2B ${ }^{-1-}$ and littermate control GluN2B ${ }^{+/+}$embryos. Embryos of either sex were used to culture hippocampal or cortical neurons.

Cell culture. GluN2B ${ }^{+/+}$, GluN2B ${ }^{+/-}$, and GluN2B ${ }^{-/-}$hippocampal and cortical neuronal cultures were prepared from embryonic day 17 (E17) to E18 mice. Briefly, hippocampi and cortex were dissected and maintained in Hibernate E (Brain Bits) supplemented with NeuroCult SM1 (Stemcell Technologies, \#05711) at $4^{\circ} \mathrm{C}$ overnight while genotyping was performed. Tissues from the same genotype were pooled together and dissociated with papain $\left(20\right.$ units $/ \mathrm{ml}, 15 \mathrm{~min}, 37^{\circ} \mathrm{C}$; Worthington Biochemical, \#PAP) and deoxyribonuclease I $(0.20 \mathrm{mg} / \mathrm{ml}$; Invitrogen, \#18047-019).

Hippocampal neurons were plated on coverslips coated with poly-Llysine in $60 \mathrm{~mm}$ Petri dishes in minimal essential medium (MEM; SigmaAldrich, \#M0268) supplemented with $10 \%$ horse serum at an approximate density of 350,000 cells/dish. Once the neurons attached to the substrate, coverslips were inverted on top of a glial cell monolayer and maintained in neurobasal medium (Invitrogen, \#21103-049) supplemented with $2 \%$ NeuroCult SM1, 0.5 mm glutamine (Sigma-Aldrich, \#G3126), $50 \mu \mathrm{g} / \mathrm{ml}$ gentamicin (Invitrogen, \#15750-037), and insulin (20 $\mu \mathrm{g} / \mathrm{ml}$; Sigma-Aldrich, \#19278), essentially as described previously (Kaech and Banker, 2006). Cortical neurons were plated on six-well plates coated with poly-L-lysine in MEM supplemented with $10 \%$ horse serum at an approximate density of 870,000 cells/well. After $\sim 3 \mathrm{~h}$ in culture, the plating medium was replaced for supplemented neurobasal medium. Neurons were maintained at $37^{\circ} \mathrm{C}$ in a humidified incubator at $5 \% \mathrm{CO}_{2}$. Cultures were used after $14-15 \mathrm{~d}$ in vitro (DIV). When indicated, the NMDAR antagonist 2-amino-5-phosphonovalerate (APV; Tocris Bioscience, $\# 0105,100 \mu \mathrm{M})$ was added directly to the culture medium from 6 DIV every $3 \mathrm{~d}$.

For PSD isolation validation, rat cortices (E17-E18) were digested with trypsin $(0.06 \%)$ for $15 \mathrm{~min}$ at $37^{\circ} \mathrm{C}$ and plated, as in the mouse cultures, in supplemented neurobasal medium without insulin.

RNA extraction and real-time PCR. Total RNA from 15 DIV cultured cortical neurons was extracted with TRIzol reagent (Invitrogen, \#15596026) following the manufacturer's specifications. The total amount of RNA was quantified by spectrophotometry (Thermo Fisher Nanodrop 2000 ) and the quality evaluated based on the ratio of optical density at 260 and $280 \mathrm{~nm}$ and on the presence of $18 \mathrm{~S}$ and $28 \mathrm{~S}$ ribosomal RNA bands visualized by agarose gel electrophoresis.

For first-strand cDNA synthesis, $1 \mu \mathrm{g}$ of total RNA and NZY FirstStrand cDNA Synthesis Kit (Nzytech, \#MB12501) were used. For quantitative gene expression analysis, $20 \mu \mathrm{l}$ reactions were prepared with $2 \mu \mathrm{l}$ of 1:100 diluted cDNA, iQ SYBR Green Supermix (Bio-Rad, \#170-8880) and specific primers at $250 \mathrm{~nm}$. The GluN1-specific primers were $5^{\prime}$ CGGCTCTTGGAAGATACAG $3^{\prime}$ and 5' GAGTGAAGTGGTCGTTGG $3^{\prime}$, and the GluN2A-specific primers were $5^{\prime}$ CCTCTATGACATTGATGA $3^{\prime}$ and $5^{\prime}$ CTGCTAAGGTCTATCTCC $3^{\prime}$. The primers for tubulin were 5' CATCCTCACCACCCACAC 3' and 5' GGAAGCAG TGATGGAAGAC $3^{\prime}$. The fluorescent signal was measured after each elongation step of the PCR, in the iQ5 Multicolor Real-Time PCR Detection System (Bio-Rad) and was used to determine the threshold cycle 
$\left(C_{\mathrm{t}}\right)$, as described previously (Manadas et al., 2009). Melting curves were performed to detect nonspecific amplification products, a nontemplate control was included in all assays, and for each set of primers, a standard curve was performed to assess primer efficiency. Reactions were run in duplicate. The level of expression of each subunit was determined relative to the level of expression of the subunit amplified from RNA isolated from wild-type neurons from the same culture. The differences between the $C_{\mathrm{t}}$ of one condition and the control were measured after correction for primer efficiency and normalized to tubulin, the internal control (Pfaffl method).

Protein extracts. Protein extracts were prepared according to a previously described protocol (Ferreira et al., 2011). Briefly, cortical neurons were washed twice with ice-cold PBS and once more with PBS supplemented with a mixture of protease inhibitors $(0.2 \mathrm{~mm}$ PMSF, $1 \mu \mathrm{g} / \mathrm{ml}$ chymostatin, $1 \mu \mathrm{g} / \mathrm{ml}$ leupeptin, $1 \mu \mathrm{g} / \mathrm{ml}$ antipain, and $1 \mu \mathrm{g} / \mathrm{ml}$ pepstatin). The cells were then scraped into lysis buffer ( $50 \mathrm{~mm}$ Tris- $\mathrm{HCl}, \mathrm{pH}$ 7.4, 5 mM EGTA, 1 mM DTT) supplemented with the mixture of protease inhibitors. After centrifugation at $18,000 \times g$ for $30 \mathrm{~min}$ at $4^{\circ} \mathrm{C}$, the supernatant was discarded and the pellet was denaturated with $2 \times$ denaturating buffer (250 mm Tris, pH 6.8, 4\% SDS, 200 mm DTT, 40\% glycerol, and $0.01 \%$ bromophenol blue) at $95^{\circ} \mathrm{C}$ for $5 \mathrm{~min}$; then, the total volume was loaded in the gel for SDS-PAGE and Western blot analysis.

Biotinylation and purification of plasma membrane-associated proteins. Biotinylation assays were performed according to a previously described protocol (Gomes et al., 2008), with slight modifications. Cells were washed twice with PBS with calcium and magnesium $\left(\mathrm{PBS} / \mathrm{Ca}^{2+} / \mathrm{Mg}^{2+}\right.$ : $137 \mathrm{~mm} \mathrm{NaCl} ; 2.7 \mathrm{~mm} \mathrm{KCl} ; 1.8 \mathrm{~mm} \mathrm{KH}_{2} \mathrm{PO}_{4} ; 10 \mathrm{~mm} \mathrm{Na}_{2} \mathrm{HPO}_{4}$; plus 0.5 $\mathrm{mM} \mathrm{MgCl} ; 1 \mathrm{mM} \mathrm{CaCl}_{2}$, pH 7.4), followed by incubation with 0.3 to 0.5 $\mathrm{mg} / \mathrm{ml} \mathrm{EZ} \mathrm{Link} \mathrm{Sulfo-NHS-SS-Biotin} \mathrm{(Pierce,} \mathrm{\# 21331)} \mathrm{for} 40 \mathrm{~min}$ at $4^{\circ} \mathrm{C}$ under mild shaking. Cells were then washed twice with $\mathrm{PBS} / \mathrm{Ca}^{2+} / \mathrm{Mg}^{2+}$ supplemented with glycine $(100 \mathrm{~mm})$. After a $45 \mathrm{~min}$ incubation in this solution, cells were lysed with a hypotonic buffer (same as above) supplemented with protease inhibitors, followed by a $30 \mathrm{~min}$ incubation on ice and brief sonication. Cellular extracts were then incubated with $1 \%$ DOC, $\mathrm{pH} 9.0,1 \mathrm{~h}$ at $37^{\circ} \mathrm{C}$, centrifuged at $18,000 \times g$ for $30 \mathrm{~min}$ at $4^{\circ} \mathrm{C}$, and the pellet was discarded. NeutrAvidin Plus UltraLink Resin (Pierce, \#53151) was added to equal amounts of supernatant fluid $(2.5 \mu \mathrm{l} / 10 \mu \mathrm{g}$ of total protein) and incubated for $2 \mathrm{~h}$ at $4^{\circ} \mathrm{C}$ with mild shaking (orbital shaker). The beads were washed four times with lysis buffer by centrifugation $(2500 \times g, 3 \mathrm{~min})$. The samples were eluted with $2 \times$ denaturating buffer, boiled at $95^{\circ} \mathrm{C}$ for $5 \mathrm{~min}$, and centrifuged into a tube collector with a $0.45 \mu \mathrm{m}$ filter.

SDS-PAGE and immunoblotting. The extracts obtained were resolved by SDS-PAGE in $8 \%$ polyacrylamide gels and immunoblotted as described previously (Gomes et al., 2008). Membranes were blocked for $1 \mathrm{~h}$ at room temperature in Tris-buffered saline ( $137 \mathrm{~mm} \mathrm{NaCl}, 20 \mathrm{~mm}$ Tris$\mathrm{HCl}, \mathrm{pH} 7.6)$ containing $0.1 \%(\mathrm{v} / \mathrm{v})$ Tween $20(\mathrm{TBS}-\mathrm{T})$ and $5 \%(\mathrm{w} / \mathrm{v})$ low-fat milk and probed overnight with the primary antibodies diluted in TBS-T containing $0.5 \%$ low-fat milk at $4^{\circ} \mathrm{C}$. After five washes in TBS-T containing $0.5 \%$ low-fat milk, membranes were incubated for $1 \mathrm{~h}$ with the alkaline phosphatase-conjugated secondary antibody at room temperature. The membranes were then washed again, incubated with chemifluorescence substrate for $5 \mathrm{~min}$, and scanned with the Storm 860 scanner (GE Healthcare). Where indicated, the membranes were stripped with $0.2 \mathrm{M} \mathrm{NaOH}$ for $15 \mathrm{~min}$ and reprobed for $1 \mathrm{~h}$ at room temperature.

Immunocytochemistry and quantitation. NMDARs were labeled with a mouse anti-GluN1 antibody according to the previously described protocol (Ferreira et al., 2011) in methanol-fixed 14 DIV hippocampal neurons $\left(10 \mathrm{~min}\right.$ at $\left.-20^{\circ} \mathrm{C}\right)$. For labeling of other proteins, hippocampal neurons were fixed at $14 \mathrm{DIV}$ in $4 \%$ sucrose $/ 4 \%$ paraformaldehyde in $\mathrm{PBS}$ for $15 \mathrm{~min}$ at room temperature. The coverslips were incubated with $10 \%$ bovine serum albumin (BSA) in PBS for $1 \mathrm{~h}$ at $37^{\circ} \mathrm{C}$ to block nonspecific antibody binding, and incubated overnight with the primary antibodies in 3\% BSA at room temperature with mild shaking. Postsynaptic sites were labeled with anti-SynGAP or PSD-95 antibody and AMPARs were labeled with an antibody against the GluA1 or against the GluA2 subunit. Presynaptic sites were labeled with a guinea pig antiVGLUT1 antibody. Dendrites were stained with a chicken antibody against MAP2. Secondary antibodies were also prepared in 3\% BSA and incubated at $37^{\circ} \mathrm{C}$ for $1 \mathrm{~h}$. The coverslips were mounted in fluorescence mounting medium (Dako, no. S3023). For proteasome activation, cells were preincubated $24 \mathrm{~h}$ previous to fixation with 25 or $50 \mu \mathrm{M}$ 1-[1-(4Fluoro-phenyl)-2,5-dimethyl-1H-pyrrol-3-yl]-2-pyrrolidin-1-yl-ethanone (IU1)-47 (kind gift from Daniel Finley).

For the antibody-feeding assay, live cells were incubated with an antibody against the $\mathrm{N}$-terminal of GluA1 for $1 \mathrm{~h}$ at $4^{\circ} \mathrm{C}$. Antibody uptake was allowed for $30 \mathrm{~min}$ at $37^{\circ} \mathrm{C}$. Where indicated, $120 \mu \mathrm{M}$ Dynasore (Sigma-Aldrich, \#D7693) was added during the primary antibody incubation and postincubation time. For proteasome activation, cells were preincubated $30 \mathrm{~min}$ at $37^{\circ} \mathrm{C}$ with IU1-47 $(50 \mu \mathrm{M})$. Cells were washed once with PBS before fixation with $4 \%$ sucrose $/ 4 \%$ paraformaldehyde. Plasma membrane labeling was detected by staining with Alexa Fluor 488 anti-sheep under nonpermeabilizing conditions. Cells were then permeabilized with $0.25 \%$ Triton X-100, incubated with $10 \%$ BSA for $30 \mathrm{~min}$, and then internalized antibodies were detected using Alexa Fluor 568 anti-sheep. The remaining labeling proceeded as described above.

Fluorescence images of mouse hippocampal neurons were obtained with a Zeiss Axiovert $200 \mathrm{M}$ microscope or a Zeiss upright Azioskop 2 plus, a $63 \times, 1.4 \times$, or $1.25 \times$ numerical aperture oil objective, respectively, and customized filter sets. Images were acquired using an AxiocamHRm (Zeiss) camera and AxionVision imaging software or ZEN microscope software (Zeiss). For each experiment, images in each channel were captured using the same exposure time across all fixed cells; images were acquired as grayscale from individual channels and pseudocolor overlays were prepared using Adobe Photoshop. To quantify the immunocytochemistry data, hippocampal neurons were chosen randomly for image acquisition and processed using MetaMorph imaging software (8-20 cells from each condition and from each independent experiment were acquired). For each neuron, two to three dendrites were chosen for analysis from the dendritic marker image and their length was measured. To quantify the postsynaptic clusters (GluN1, GluA1, GluA2, SynGAP, and PSD-95) per dendrite length, the digital images were subjected to a user-defined intensity threshold to select clusters and measured for cluster intensity, number, and area for the selected region. The number of synaptic clusters was determined as the number of postsynaptic clusters overlapping thresholded VGLUT. All imaging and analysis were done blind to genotype and treatment condition.

Synaptic scaling assay. Cortical neurons cultured at low density were incubated at $14 \mathrm{DIV}$ for $24 \mathrm{~h}$ with $2 \mu \mathrm{M}$ tetrodotoxin citrate (TTX; Tocris Bioscience) and live stained with a sheep antibody against the $\mathrm{N}$-terminal region of GluA1 for $10 \mathrm{~min}$ at room temperature. After washing once with PBS, cells were fixed in 4\% sucrose/ $4 \%$ PFA and incubated with an anti-sheep antibody conjugated to Alexa Fluor 488 after permeabilization with $0.25 \%$ Triton X-100/PBS. The remaining antibody staining for PSD-95, VGLUT1, and MAP2 followed as described above.

Proteasomal peptidase activity assay. Cortical neurons were washed twice with ice-cold PBS buffer. The cells were then lysed in $1 \mathrm{~mm}$ EDTA, 10 mm Tris-HCl pH 7.5, 20\% glycerol, 4 mm DTT, and 2 mm ATP (100 $\mu \mathrm{l} /$ well). After sonication and centrifugation at $16,100 \times g$ for $10 \mathrm{~min}$ at $4^{\circ} \mathrm{C}$, total protein content in the supernatants was quantified using the Bio-Rad protein assay and the concentration of the samples were equalized with lysis buffer.

Chymotrypsin-like activity of the proteasome was assayed by monitoring the production of 7-amino-4-methylcoumarin (AMC) from fluorogenic peptide Suc-LLVY-AMC (Peptide Institute) accordingly to a previously described protocol (Caldeira et al., 2013). Samples $(20 \mu \mathrm{g})$ were incubated with the fluorogenic substrates, $25 \mu \mathrm{M}$ Suc-LLVY-AMC in $25 \mathrm{~mm}$ Tris- $\mathrm{HCl}, \mathrm{pH} 8.0$, and $0.5 \mathrm{~mm}$ EDTA buffer, in a final volume of $100 \mu \mathrm{l}$. The release of fluorescent AMC was measured at $37^{\circ} \mathrm{C}$ using a microplate reader SPECTRAmax Gemini EM (Molecular Devices) at an excitation wavelength of $360 \mathrm{~nm}$ and an emission wavelength of $460 \mathrm{~nm}$ for $60 \mathrm{~min}$ at $5 \mathrm{~min}$ intervals. All experiments were performed in the presence of $2 \mathrm{~mm}$ ATP. Specific activity was determined by subtracting the activity measured in the presence of $10 \mu \mathrm{M}$ MG132 (Calbiochem), a proteasome inhibitor.

Subcellular fractionation of high-density cultured neurons. Protein extracts were prepared from 14-15 DIV rat or mouse cortical neurons. 
Briefly, cells were washed with ice-cold HEPES-buffered sucrose solution (0.32 $\mathrm{m}$ sucrose, 4 mM HEPES, $\mathrm{pH} 7.4$ ) and then lysed in the same buffer supplemented with a mixture of protease ( $0.2 \mathrm{~mm}$ PMSF), $1 \mu \mathrm{g} / \mathrm{ml}$ chymostatin, $1 \mu \mathrm{g} / \mathrm{ml}$ leupeptin, $1 \mu \mathrm{g} / \mathrm{ml}$ antipain, and $1 \mu \mathrm{g} / \mathrm{ml}$ pepstatin (CLAP) and phosphatase (0.1 $\mathrm{mm} \mathrm{Na}_{3} \mathrm{VO}_{4}$ and $\left.50 \mathrm{~mm} \mathrm{NaF}\right)$ inhibitors. The collected cells were homogenized in a glass-Teflon homogenizer ( $\sim 30$ strokes) and stored at $-80^{\circ} \mathrm{C}$.

The procedure for purification of synaptic fractions was adapted from Peca et al. (2011) and modified according to the protocol described by Ehlers (2003) for high-density cultured neurons. PSDs were isolated from 14-15 DIV high-density cortical rat neurons. Briefly, the culture homogenate was centrifuged at $900 \times g$ for $15 \mathrm{~min}$ to obtain the nonnuclear fraction (S1). The resultant supernatant was centrifuged at $18,000 \times g$ for 15 min to yield the crude synaptosomal pellet (P2). P2 was resuspended in HEPES-buffered sucrose solution and centrifuged at $18,000 \times g$ for 15 min to yield the washed crude synaptosomal fraction. This fraction was submitted to hypo-osmotic shock by resuspending the pellet in HEPES buffer (4 mM HEPES, pH 7.4, plus protease and phosphatase inhibitors) and incubated $1-2 \mathrm{~h}$ with orbital rotation at $4^{\circ} \mathrm{C}$. The lysate was centrifuged at $25,000 \times g$ for $20 \mathrm{~min}$ and the pellet (lysed synaptosomal membrane fraction) was resuspended in HEPES-buffered sucrose solution (without $\mathrm{Na}_{3} \mathrm{VO}_{4}$ ), placed on top of a discontinuous sucrose gradient $(0.8,1,1.2 \mathrm{M})$, and spun at $150,000 \times g$ for $2 \mathrm{~h}$ in a swinging bucket rotor. Synaptic plasma membranes (SPMs) were recovered between the $1.0 \mathrm{M}$ and $1.2 \mathrm{~m}$ layers, diluted to $0.32 \mathrm{M}$ sucrose, and centrifuged at $150,000 \times g$ for $30 \mathrm{~min}$. SPMs were resuspended in HEPES/EDTA buffer (50 mm HEPES, 2 mm EDTA, pH 7.4) containing protease and phosphatase inhibitors and solubilized with $0.5 \%$ Triton $\mathrm{X}-100$ for $15 \mathrm{~min}$ with orbital rotation at $4^{\circ} \mathrm{C}$, followed by $20 \mathrm{~min}$ centrifugation at $200,000 \times g$. The remaining pellet, corresponding to the PSDs, was resuspended in HEPES/EDTA buffer containing 0.5\% SDS. All experimental procedures and centrifugations were performed on ice or at $4^{\circ} \mathrm{C}$. For protein quantification, samples were boiled for $5 \mathrm{~min}$ at $95^{\circ} \mathrm{C}$. Protein concentration was determined by the Bio-Rad method and samples were denatured with $5 \times$ denaturating buffer $[125 \mathrm{~mm}$ Tris, $\mathrm{pH}$ 6.8, $100 \mathrm{~mm}$ glycine, 10\% SDS, $200 \mathrm{~mm}$ DTT, 40\% glycerol, $3 \mathrm{~mm}$ $\mathrm{Na}_{3} \mathrm{VO}_{4}$, and $0.01 \%$ bromophenol blue] and separated by SDS-PAGE or subjected to trypsin digestion and ITRAQ reagent tagging for proteomic relative quantification.

Protein digestion and iTRAQ labeling. In one 8-plex iTRAQ experiment, five control PSD samples (three wild-type and two heterozygous cortical cultures) were compared with PSD samples isolated from three GluN2B ${ }^{-1-}$ cortical cultures. The digestion and iTRAQ labeling of the PSDs have been described previously ( $\mathrm{Li}$ et al., 2007; Klemmer et al., 2011). In short, for each sample, $10 \mu \mathrm{g}$ of PSD protein was solubilized in 0.85\% RapiGest (Waters) reconstituted with dissolution buffer (iTRAQ reagent kit; $\mathrm{AB}$ Sciex). Cleavage reagent (iTRAQ reagent kit; $\mathrm{AB}$ Sciex) was added and incubated at $55^{\circ} \mathrm{C}$ for $1 \mathrm{~h}$, after which Cys blocking reagent (iTRAQ reagent kit; AB Sciex) was added and samples were vortexed for $10 \mathrm{~min}$. Subsequently, trypsin (sequencing grade; Promega) was added and incubated overnight at $37^{\circ} \mathrm{C}$. The trypsinized peptides were then tagged with iTRAQ reagents dissolved in ethanol. After incubation for $3 \mathrm{~h}$, the samples were pooled and acidified with $10 \%$ trifluoroacetic acid to $\mathrm{pH} 2.5-3$. After $1 \mathrm{~h}$, the sample was centrifuged and the supernatant was dried in a SpeedVac. One 8-plex iTRAQ experiment was performed to cover the eight samples. Three GluN2B ${ }^{+/+}$samples were labeled with iTRAQ reagents 113, 114, and 115; GluN2B ${ }^{+/-}$were labeled with iTRAQ reagents 116 and 117 ; and three GluN2B ${ }^{-1-}$ samples were labeled with iTRAQ reagents 118, 119, and 121 (see Fig. 7C).

$2 \mathrm{D}$ liquid chromatography. The iTRAQ-labeled samples were combined, dried, dissolved in loading buffer $(20 \%$ acetonitrile, $10 \mathrm{~mm}$ $\mathrm{KH}_{2} \mathrm{PO}_{4}, \mathrm{pH}$ 2.9), and injected into a strong cation exchange column $(2.1 \times 150 \mathrm{~mm}$ PolySUlFOETHYL A column; PolyLC). Peptides were eluted with a linear gradient of $0-500 \mathrm{~mm} \mathrm{KCl}$ in $20 \%$ acetonitrile, $10 \mathrm{~mm}$ $\mathrm{KH}_{2} \mathrm{PO}_{4}, \mathrm{pH} 2.9,>25 \mathrm{~min}$ at a flow rate of $200 \mu \mathrm{l} / \mathrm{min}$. Fractions were collected at $1 \mathrm{~min}$ intervals and dried in a SpeedVac. The peptides were redissolved in $0.1 \%$ TFA, delivered with a FAMOS autosampler at 30 $\mu \mathrm{l} / \mathrm{min}$ to a reverse phase C18 trap column $(1 \mathrm{~mm} \times 300-\mu \mathrm{m}$-inner diameter column), and separated on an analytical capillary reverse phase
C18 column $(150 \mathrm{~mm} \times 100 \mu \mathrm{m}$ inner diameter column $)$ at $400 \mathrm{nl} / \mathrm{min}$ using the LC-Packing Ultimate system. The peptides were separated using a linear increase in a concentration of acetonitrile from 6 to $45 \%$ in 50 $\mathrm{min}$ and to $90 \%$ in $1 \mathrm{~min}$. The eluent was mixed with matrix (7 mg of recrystallized $\alpha$-cyanohydroxycinnamic acid in $1 \mathrm{ml}$ of $50 \%$ acetonitrile, $0.1 \%$ TFA, $10 \mathrm{~mm}$ ammonium dicitrate) delivered at a flow rate of 1.5 $\mu \mathrm{l} / \mathrm{min}$ and deposited offline to an Applied Biosystems metal target every $15 \mathrm{~s}$ using an automatic robot (Probot; Dionex).

MALDI-MS/MS. The sample was analyzed on an ABI 4800 proteomics analyzer (AB Sciex). Peptide collision induced dissociation was performed at $2 \mathrm{kV}$; the collision gas was air. MS/MS spectra were each collected from 2500 laser shots. Peptides with a signal-to-noise ratio $>50$ at the MS mode were selected for an MS/MS experiment; a maximum of $25 \mathrm{MS} / \mathrm{MS}$ was allowed per spot. The precursor mass window was 200 relative to resolution (full width at half maximum).

Protein identification and quantitation. MS/MS spectra were searched against a mouse database (IPI_mouse V3.79) with the ProteinPilot software (version 3.0) using the ParagonTM algorithm (version 3.0.0.0) as the search engine. The search parameters were set to iTRAQ 8plex (peptide labeled), cysteine modification by MMTS, and trypsin digest. The detected protein threshold unused protscore (confidence) in the software was set to 0.10 to achieve a $20 \%$ confidence. The bias correction option was executed and iTRAQ isotope correction factors were included as provided by the company. The fold difference between labeled peptides (denominator: iTRAQ label 113) was calculated during the search. The identified proteins with unused value $\leq 4$, corresponding to proteins that were identified with $<2$ peptides with $\geq 99 \%$ of confidence, were excluded from quantitation. Finally, the three mutant and three wildtype plus two heterozygous protein means were used to calculate the average difference between control $\left[\mathrm{GluN}_{2} \mathrm{~B}^{+/+}\right.$and GluN2B $\left.{ }^{+/-}\right]$and GluN2B $^{-1-}$ samples.

\section{Results}

NMDAR synaptic clustering in hippocampal neurons lacking the GluN2B or the GluN2A subunits

To study the role of the GluN2B subunit of NMDARs, we cultured hippocampal neurons from GluN2B ${ }^{-/-}$and GluN2B ${ }^{+/+}$ embryos obtained by mating GluN2B ${ }^{+/-}$mice. To assess the clustering of NMDARs, we immunostained low-density hippocampal cultures at 15 DIV with an antibody against the GluN1 obligatory subunit (Fig. 1A,B). Synaptic clusters were evaluated as the GluN1 clusters that colocalized with the synaptic markers SynGAP (postsynaptic marker) and VGLUT (presynaptic marker). GluN1 clusters juxtaposed to VGLUT clusters were quantified. Under control conditions (Fig. $1 C-E$, white bars), we observed a dramatic decrease in GluN1 synaptic clustering $(p<$ 0.001 , one-way ANOVA followed by Bonferroni's multiplecomparisons test) in GluN2B ${ }^{-/-}$neurons compared with wildtype neurons, in the number (Fig. 1C), area (Fig. 1D) and total intensity (Fig. $1 E$ ) of clusters. The density of synaptic GluN1 clusters was reduced by 5.8 -fold in GluN2 $\mathrm{B}^{-1-}$ compared with wild-type neurons. We did not observe any significant changes on the presynaptic marker VGLUT clustering between genotypes (data not shown). When we chronically incubated wild-type cultures with APV (100 $\mu \mathrm{M})$ from DIV 6, we observed an increase in NMDAR clustering (1.93-fold for the number, 2.5-fold for the area, and 2.95-fold for the intensity of GluN1 clusters, $p<0.001$, one-way ANOVA followed by Bonferroni's multiple-comparisons test) compared with unstimulated control cultures (Fig. $1 C-E$, gray bars), in agreement with the homeostatic compensatory increase in NMDAR clustering upon chronic incubation with an NMDAR antagonist previously described in rat and mouse neurons (Rao and Craig, 1997; Ferreira et al., 2011). However, when we chronically incubated GluN2B ${ }^{-/-}$hippocampal neurons with APV, no significant changes were found for the GluN1 cluster number, area, or intensity compared with unstimulated cultures (Fig. 


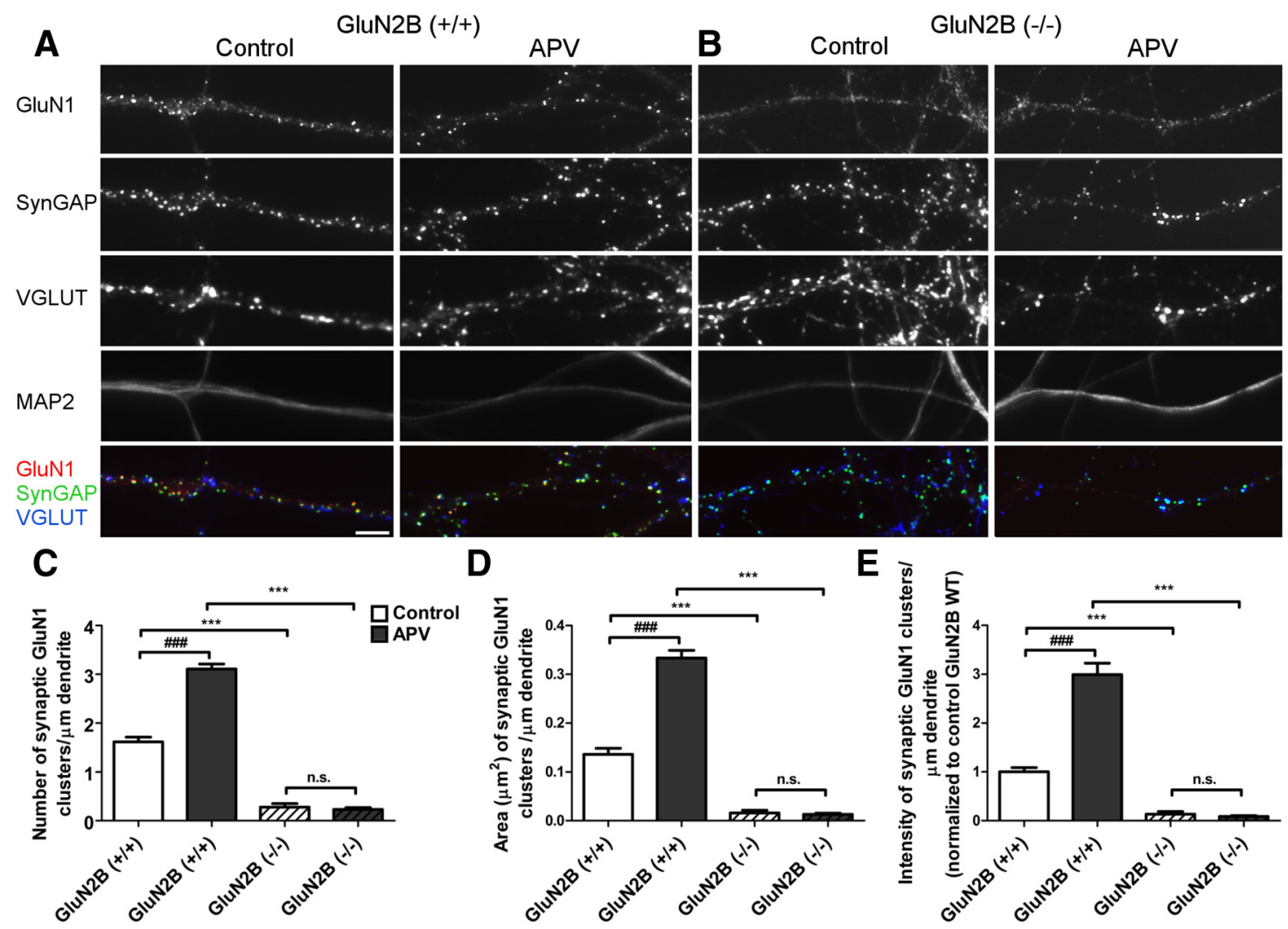

Figure 1. GluN1 synaptic clusters are dramatically decreased in GluN2B ${ }^{-1-}$ hippocampal neurons. Low-density hippocampal cultures from wild-type $\left(\boldsymbol{A} ; \boldsymbol{G}^{-G l u N 2 B}{ }^{+/+}\right)$or GluN2B knock-out $(\boldsymbol{B}$; GluN2B ${ }^{-1-}$ ) mice were fixed at 14 DIV and immunostained for GluN1 (red merge), for the excitatory postsynaptic protein SynGAP (green merge), for the excitatory presynaptic marker VGLUT (blue merge), and for the dendritic marker MAP2. Cultured neurons were treated with the NMDA receptor blocker APV (100 $\mu \mathrm{M}$ ) from 6 DIV to increase synaptic clustering of NMDARs homeostatically. GluN2B ${ }^{-/-}$neurons show a dramatic decrease of GluN1 synaptic clusters both under control and activity blockade conditions. Scale bar, $5 \mu \mathrm{m}$. The number $(\boldsymbol{C})$, total area $(\boldsymbol{D})$, and integrated intensity $(\boldsymbol{E})$ of synaptic GluN1 clusters juxtaposed to VGLUT per dendritic length were analyzed. Data are presented as mean \pm SEM, $n=40$ to 48 cells from three independent experiments. ${ }^{* * *}$ Comparison between GluN2B ${ }^{+/+}$and ${ }^{-/-}$; \#\#\#comparison between control and APV conditions, $p<0.0001$, n.s., $p>0.05$, one-way ANOVA followed by Bonferroni's multiplecomparisons test.

$1 C-E, p>0.05$, one-way ANOVA followed by Bonferroni's multiple-comparisons test). The absence of homeostatic activity regulation resulted in a difference of 13.5 -fold in synaptic GluN1 clusters in GluN2B ${ }^{-1-}$ compared with wild-type neurons under conditions of activity blockade.

Interestingly, in GluN2 $\mathrm{A}^{-1-}$ hippocampal cultures, GluN1 clusters were indistinguishable from those in wild-type GluN2A $\mathrm{A}^{+/+}$neurons (Fig. 2), both in control conditions and after chronic incubation with APV (Fig. $2 C-E$, white bars, $p>$ 0.05, one-way ANOVA followed by Bonferroni's multiplecomparisons test). In addition, when cultures of either genotype were chronically incubated with APV, the homeostatic compensatory increase in NMDARs was observed (Fig. 2). In both GluN2 $^{+/+}$and GluN2A ${ }^{-/-}$hippocampal neurons, there was a dramatic increase in the synaptic clustering of NMDARs in cultures treated with APV from DIV 6 (respectively for GluN2A ${ }^{+/+}$ and GluN2 $\mathrm{A}^{-1-}, 1.99$ - and 2.32-fold for cluster number, Figure $2 C$; 2.89- and 4.09-fold for cluster area, Figure 2D; and 3.18- and 5.25-fold for cluster intensity, Figure 2E; $p<0.001$, one-way ANOVA followed by Bonferroni's multiple-comparisons test, compared with control cultures of the same genotype). There was no significant difference in number of GluN1 clusters in GluN2A ${ }^{-1-}$ compared with wild-type neurons after the chronic incubation with NMDAR antagonist (Fig. 2C, gray bars).

Together, these results indicate that the GluN2B subunit is essential for the targeting and/or maintenance of NMDARs to/in the synapse and for the homeostatic response to chronic activity blockade promoted by the prolonged incubation with the NMDAR antagonist, whereas both synaptic NMDAR clustering and the homeostatic synaptic accumulation of NMDARs occur in the absence of GluN2A.

\section{NMDAR total and cell surface levels in GluN2B ${ }^{-1-}$ cortical neurons}

We next analyzed the levels of GluN1 and GluN2A in wild-type, GluN2B $^{+/-}$, and GluN2B ${ }^{-1-}$ neurons at 7 and 15 DIV (Fig. $3 A-D)$ before and after the peak of synaptogenesis in these cultures, respectively (Zhang and Benson, 2001). For the biochemical assays, we used high-density cortical cultures due to the limiting number of hippocampal neurons that can be obtained from genotyped embryos. Using specific antibodies against the GluN1 and the GluN2A NMDAR subunits (Fig. $3 A, B$ ), we observed that GluN1 levels were decreased in GluN2B ${ }^{-1-}$ cortical neurons compared with wild-type neurons, both at 7 and 15 DIV (Fig. $3 C, p<0.001$ and $p<0.05$, respectively, one-way ANOVA followed by Bonferroni's multiple-comparisons test). Consistent with the literature (Monyer et al., 1994; Sheng et al., 1994), at 7 DIV, we detected low levels of the GluN2A subunit in GluN2B ${ }^{+/+}$neurons, which increased dramatically (7.6-fold) at 15 DIV (Fig. 3D). Although no differences between genotypes were observed at $7 \mathrm{DIV}$, at $15 \mathrm{DIV}$, GluN2A levels were significantly decreased (0.54-fold change) in GluN2B ${ }^{-1-}$ neurons 


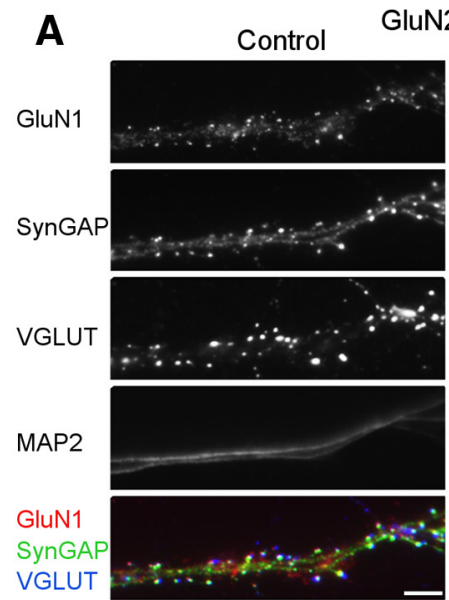

C

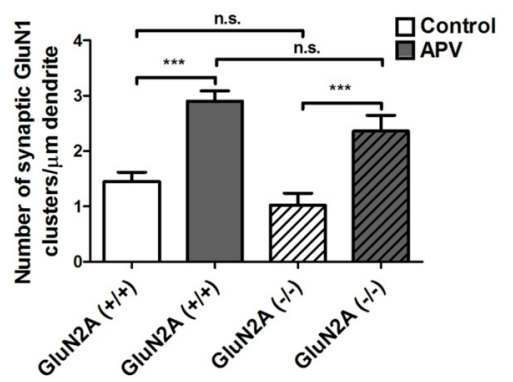

APV

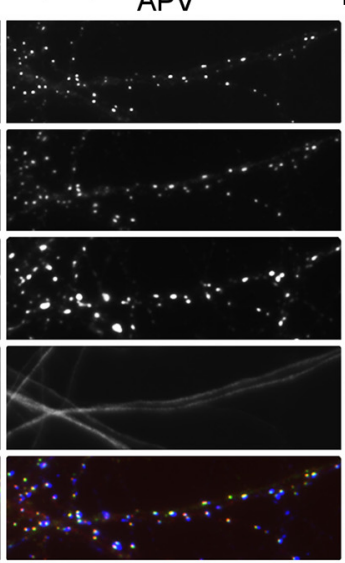

D

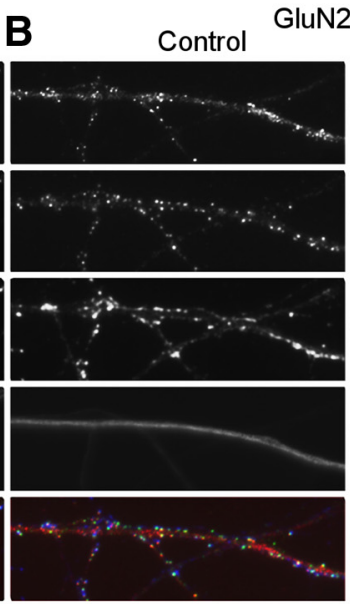

APV

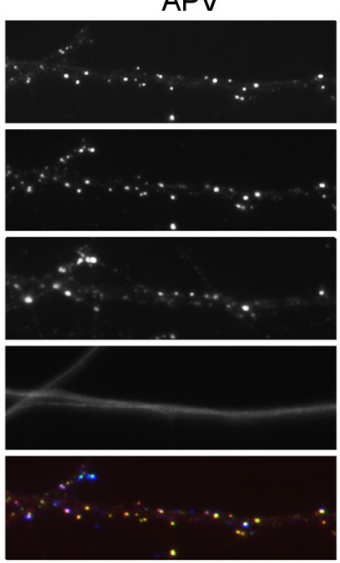

E

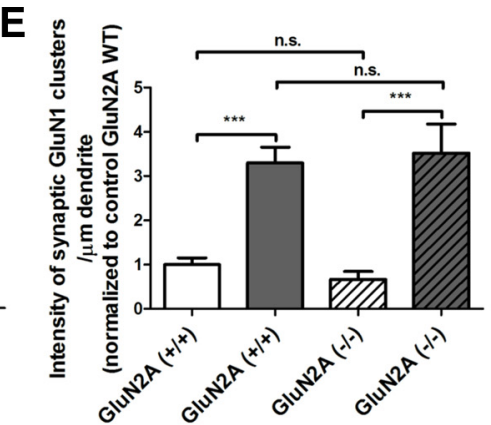

Figure 2. GluN1 synaptic clusters are not changed in GluN2A ${ }^{-/-}$hippocampal neurons. Low-density hippocampal cultures from wild-type $\left(\boldsymbol{A}\right.$; GluN2A $\left.{ }^{+/+}\right)$or GluN2A knock-out $(\boldsymbol{B}$; GluN2A ${ }^{-1-}$ ) mice were fixed at 14 DIV and immunostained for GluN1 (red merge), for the excitatory postsynaptic protein SynGAP (green merge), for the excitatory presynaptic marker VGLUT (blue merge), and for the dendritic marker MAP2. Cultured neurons were treated with the NMDAR blocker APV (100 $\mu$ m) from 6 DIV to increase synaptic clustering of NMDARs homeostatically. Scale bar, $5 \mu \mathrm{m}$. The number $(\boldsymbol{C})$, total area $(\boldsymbol{D})$, and integrated intensity $(\boldsymbol{E})$ of synaptic GluN1 clusters opposed to VGLUT per dendritic length were analyzed. Data are presented as mean \pm SEM, $n=16$ cells from two independent experiments. ${ }^{* *}$ Comparison between control and APV conditions, $p<0.0001$, n.s., $p>0.05$ comparison between GluN2A ${ }^{+/+}$and ${ }^{-/-}$, one-way ANOVA followed by Bonferroni's multiple-comparisons test.

compared with the same age wild-type neurons (Fig. $3 D, p<$ 0.01, one-way ANOVA followed by Bonferroni's multiplecomparisons test). Although GluN2A levels were decreased in GluN2B $^{-/-}$cortical neurons, its expression was still being developmentally regulated in these mice because its levels were significantly increased at 15 DIV compared with 7 DIV $(p<0.05$, one-way ANOVA followed by Bonferroni's multiple-comparisons test). The differences in protein expression levels described above are not due to alterations in the mRNA levels of GluN1 (Fig. $3 E$ ) or GluN2A (Fig. $3 F$ ) in the GluN2B ${ }^{-/-}$neurons because we observed no significant changes $(p>0.05$, paired $t$ test) in the mRNA levels of GluN1 or GluN2A in GluN2B ${ }^{-/-}$neurons relative to wild-type cultures. The decreased GluN1 and GluN2A expression levels in GluN2B ${ }^{-1-}$ neurons suggest that GluN1/GluN2A-NMDARs are unstable in the absence of GluN2B.

To evaluate the surface expression of NMDARs in neurons lacking the GluN2B subunit, we biotinylated cell surface proteins in GluN2B ${ }^{+/+}$and GluN2B ${ }^{-1-}$ cortical neurons, affinitypurified biotinylated proteins, and evaluated GluN1 levels both in total and in purified cell surface fractions (Fig. $3 G$ ) normalized to transferrin receptor levels. GluN1 was decreased to $19.47 \pm$ $7.32 \%$ (total fraction) and $19.89 \pm 5.25 \%$ (biotinylated fraction) in GluN2B ${ }^{-1-}$ neurons compared with GluN2B ${ }^{+/+}$neurons $(p<0.01$, paired $t$ test; Fig. $3 H)$. These results are consistent with the observation that GluN1 synaptic clusters are dramatically reduced in GluN2B ${ }^{-/-}$hippocampal neurons compared with wild-type neurons (Fig. 1).

\section{AMPAR traffic is altered in GluN2B ${ }^{-/-}$neurons}

Accumulated evidence obtained by different studies suggests that the traffic of AMPAR subunits is altered in GluN2B ${ }^{-1-}$ neurons (Hall et al., 2007; Ultanir et al., 2007; Adesnik et al., 2008; Hall and Ghosh, 2008; Gray et al., 2011; Wang et al., 2011). Most of these studies have used electrophysiology approaches to study AMPAR function in neurons lacking GluN2B and found AMPAR-mediated mEPSCs to be upregulated in the absence of GluN2B (Hall et al., 2007; Ultanir et al., 2007; Adesnik et al., 2008; Hall and Ghosh, 2008). We used immunocytochemistry and biochemical approaches to further explore this effect.

Biotinylation studies in GluN2 $\mathrm{B}^{-/-}$and wild-type cortical neurons showed an increase in GluA1 and GluA2 AMPAR subunits in the cell surface fraction in GluN2B ${ }^{-/-}$compared with wild-type neurons (Fig. $4 A-C$ ), although the effect was statistically significant only for the GluA1 subunit (Fig. $4 B, p<0.05$, paired $t$ test). In a complementary approach, we immunostained GluN2B ${ }^{-1-}$ and wild-type hippocampal neurons with antibodies against GluA1 (Fig. 4D) or GluA2 (Fig. 4F) and quantified the synaptic AMPARs colocalizing with VGLUT (Fig. 4E, G). GluA1 and GluA2 synaptic clusters were significantly increased in GluN2B $^{-1-}$ hippocampal neurons compared with wild-type neurons (Fig. $4 E, G, p<0.01$ and $p<0.001$, $t$ test, respectively, for GluA1 and GluA2), in agreement with the electrophysiology data reported by others (Hall et al., 2007; Ultanir et al., 2007; Adesnik et al., 2008; Hall and Ghosh, 2008; Gray et al., 2011; Wang et al., 2011). Together, these results support the hypothesis that cell surface and 
synaptic levels of AMPARs are enhanced in the absence of GluN2B-NMDARs.

Because phosphorylation of GluA subunits regulates the plasma membrane and synaptic trafficking of AMPARs (for review, see Santos et al., 2009), we investigated whether AMPAR subunit phosphorylation levels are altered in GluN2B ${ }^{-1-}$ neurons. We evaluated GluA1 and GluA2 phosphorylation levels by Western blot using phosphospecific antibodies against the GluA1-Ser 831, GluA1-Ser 845, and GluA1-Thr 840 phosphorylation sites. We observed that the phosphorylation of Ser 831 was significantly decreased in GluN2B $^{-1-}$ cortical neurons to $54.76 \pm$ 12.2\% ( $p<0.05 t$ test; Fig. $4 H)$, whereas the other GluA1 phosphorylation sites were not significantly changed (data not shown). Phosphorylation of Ser 880 in GluA2, which has been implicated in LTD through the regulation of AMPAR endocytosis (Matsuda et al., 1999; Chung et al., 2000), was significantly decreased to $58.78 \pm 7.96 \%(p<0.05 t$ test; Fig. $4 I)$ in GluN2B ${ }^{-1-}$ neurons, consistent with the increased synaptic localization of GluA2 clusters (Fig. 4F, G). An important regulator of AMPARs is stargazin, a member of the transmembrane AMPAR-associated protein (TARP) family that is known for its role in AMPAR surface expression (Tomita et al., 2003) and diffusional trapping of the receptors upon phosphorylation (Opazo et al., 2010). In GluN2B ${ }^{-/-}$ cortical neurons, there was a small but significant decrease in stargazin phosphorylation at Ser $239 / 240$ to $92.45 \pm$ 1.94\% ( $p<0.05 t$ test; Fig. $4 J)$, whereas total stargazin levels were unchanged. Because GluA1-Ser831 and stargazin are CaMKII/PKC substrates and GluA2Ser880 is phosphorylated by PKC, we tested for changes in the activity of CaMKII and PKC in GluN2B ${ }^{-/-}$neurons compared with wild-type neurons. We did not observe any changes between genotypes in the phosphorylation levels of CaMKII at Thr 286/287 ( $p>0.05 t$ test) nor in the content of phospho-PKC substrates $(p>0.05 t$ test) that we measured using an antibody that detects phosphorylation of proteins at phospho-Ser PKC substrate motifs in cortical neurons (data not shown).

Synaptic scaling is a form of homeostatic plasticity in which neurons adjust their synaptic strength in a cell-wide manner in response to prolonged alterations in network activity, in part by changing AMPA receptor content at excitatory synapses (Turrigiano et al., 1998). We tested whether GluN2B could
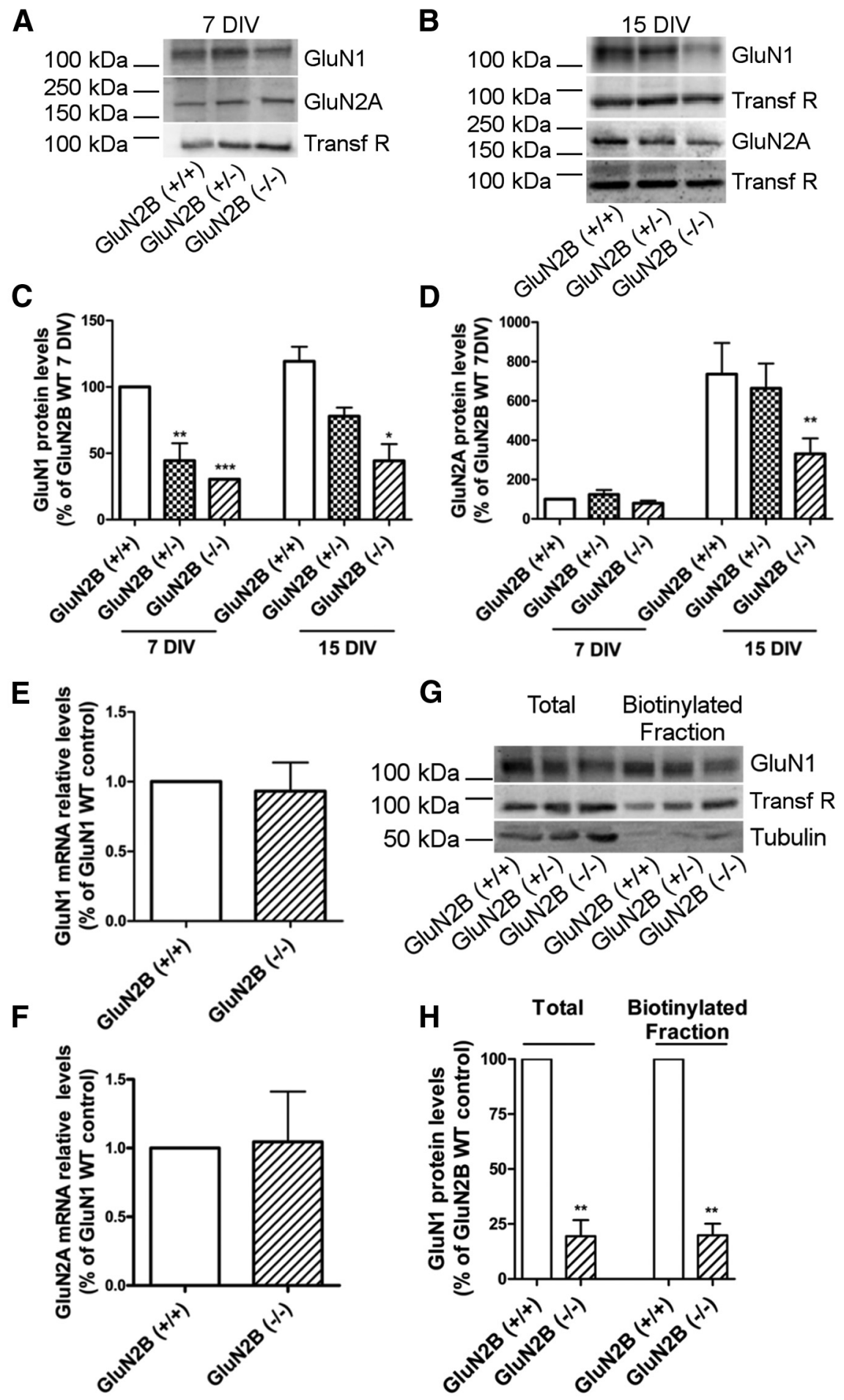

Figure 3. GluN1 and GluN2A total and surface levels are decreased in GluN2B ${ }^{-1-}$ cortical neurons. Membrane extracts from cortical cultures from GluN2B ${ }^{+/+}$, heterozygous GluN2B ${ }^{+/-}$, and GluN2B ${ }^{-1-}$ mice at 7 DIV $(\boldsymbol{A})$ or 15 DIV $(\boldsymbol{B})$ were used to evaluate total GluN1 and GluN2A protein levels by Western blot. C, D, Total GluN1 and GluN2A protein levels were normalized with transferrin receptor (TransfR) levels and presented as percentage of the protein levels detected in wild-type neurons 7 DIV. Data are presented as mean \pm SEM from three to four independent experiments. ${ }^{*} p<0.05,{ }^{* *} p<0.01,{ }^{* *} p<0.0001$, one-way ANOVA followed by Bonferroni's multiple-comparisons test. Relative mRNA levels for GluN1 $(\boldsymbol{E})$ and GluN2A $(\boldsymbol{F})$ in 15 DIV mouse cortical cultures were determined by quantitative real-time $P C R$. Data are presented as mean $\pm S E M$ from five independent experiments for GluN1 mRNA levels and four independent experiments for GluN2A mRNA levels. $p>0.05$, paired $t$ test. G, Total extracts and cell surface biotinylated-purified proteins isolated from high-density cortical culture 15 DIV from GluN2B ${ }^{+/+}$and ${ }^{-/-}$mice were assayed by Western blot using an antibody against GluN1. $\boldsymbol{H}$, Transferrin receptor protein levels were used as a loading control. GluN1 levels are normalized to GluN1 levels in wild-type neurons. Data are presented as mean \pm SEM from three independent experiments. ${ }^{* *} p<0.01$, paired $t$ test. 

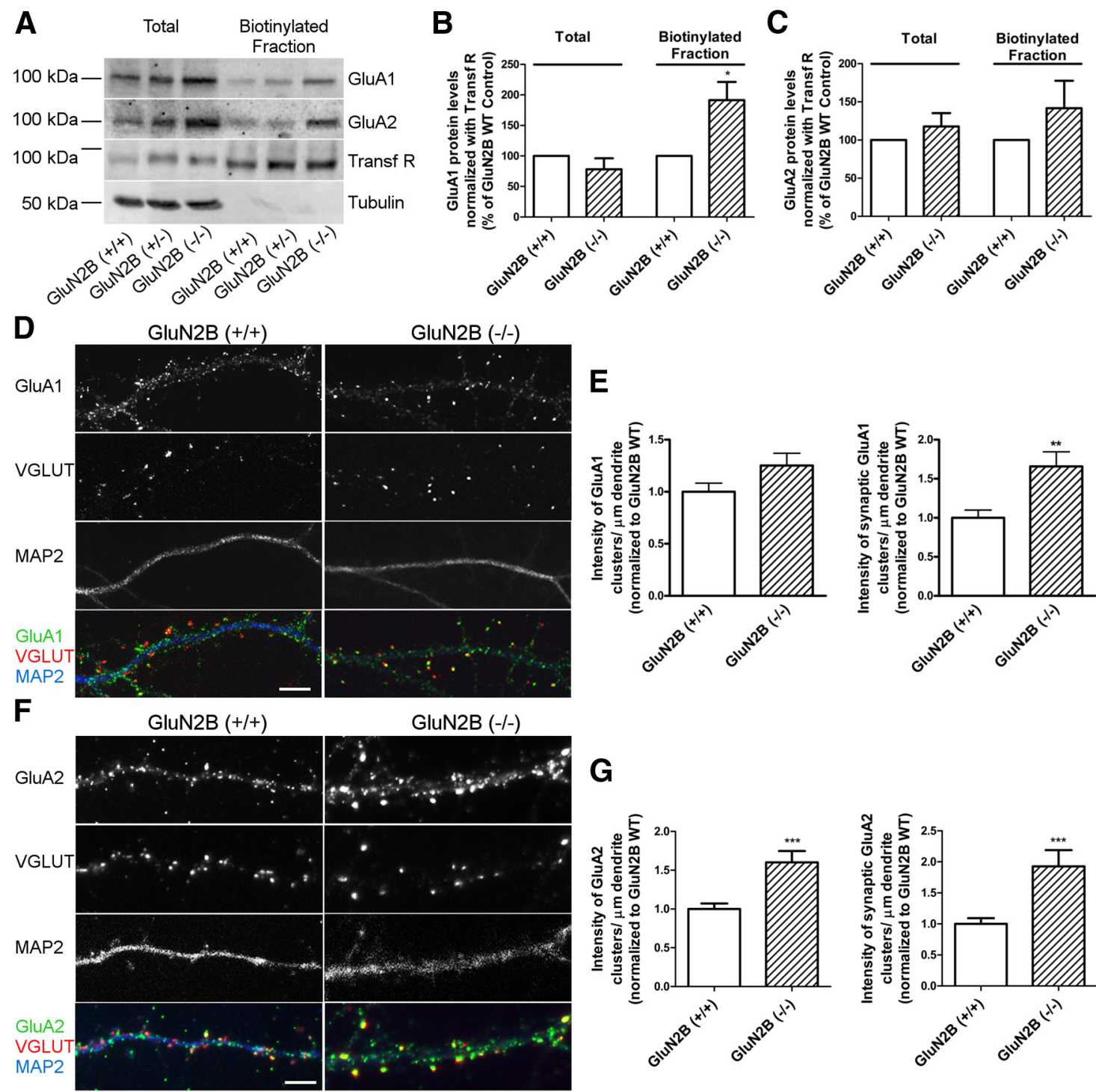

GluN2B (-/-)
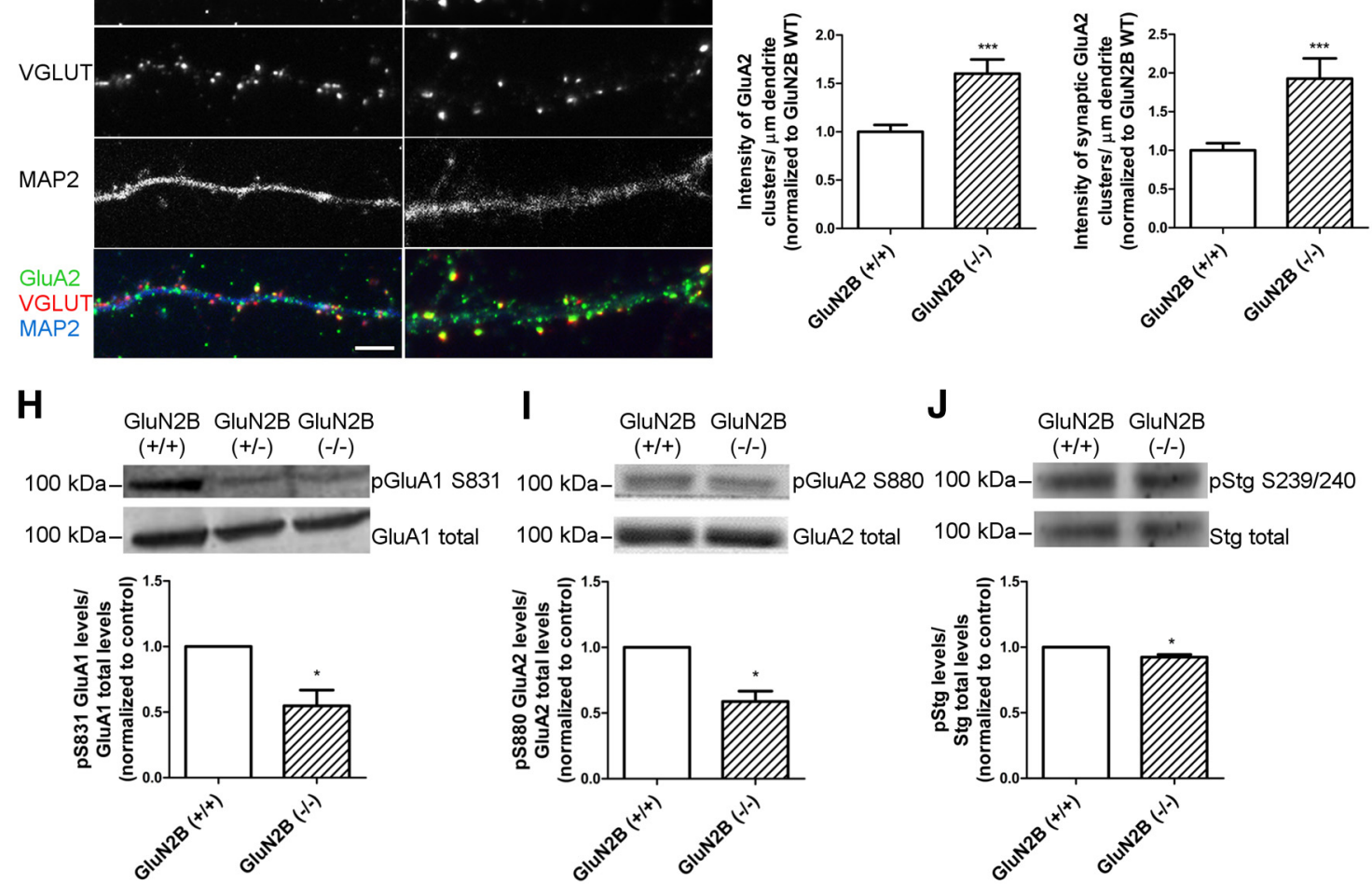

Figure 4. AMPAR synaptic expression is increased in GluN2B ${ }^{-1-}$ hippocampal neurons. $\boldsymbol{A}$, Total extracts and cell surface biotinylated proteins isolated from high-density cortical cultures 15 DIV from wild-type (GluN2B ${ }^{+/+}$) and GluN2B ${ }^{-1-}$ mice were probed by Western blot using antibodies against GluA1 and GluA2. B, C, Total protein levels were normalized with transferrin receptor (Transf R) levels and presented as percentage of protein levels in wild-type neurons. Data are presented as mean \pm SEM from six independent experiments for GluA1 expression levels and five independent experiments for GluA2 expression levels. ${ }^{*} p<0.05$, paired t test. $\boldsymbol{D}$, Low-density hippocampal cultures from wild-type or GluN2B ${ }^{-1-}$ mice were fixed at 14 DIV and immunostained for GluA1 (green merge), the excitatory presynaptic marker VGLUT (red merge), and the dendritic marker MAP2 (blue merge). $\boldsymbol{E}$, The integrated intensity of total and synaptic (apposed to VGLUT) GluA1 clusters per dendritic length were analyzed. Data are presented as mean \pm SEM, $n=57$ cells from three independent experiments; ${ }^{* *} p<0.01, t$ test. Scale bar, $5 \mu \mathrm{m}$. F, Low-density hippocampal cultures from wild-type or GluN2B ${ }^{-1-}$ mice were fixed at 14 DIV and immunostained for GluA2 (green merge), the excitatory presynaptic marker VGLUT (red merge), and the dendritic marker MAP2 (blue merge). Scale bar, $5 \mu$ m. G, The integrated intensity of total and synaptic (apposed to VGLUT) GluA2 clusters per dendritic length were analyzed. Data are presented as mean $\pm \mathbf{S E M}, n=76$ cells from four independent experiments. ${ }^{* * *} p<0.0001, t$ test. $\boldsymbol{H}, \boldsymbol{I}, \boldsymbol{J}$, Membrane extracts from cortical cultures from GluN2B ${ }^{+/+}$and ${ }^{-/-}$mice at 15 DIV were used to evaluate phosphorylation of S831 on GluA1 (H), S880 on GluA2 (I), and of S239/240 on Stargazin (J). Total levels of the respective protein were used as loading control and data were normalized to $\mathrm{GluN} 2 \mathrm{~B}^{+/+}$control levels. Data are presented as mean \pm SEM from four independent experiments. ${ }^{*} p<0.05, t$ test. 

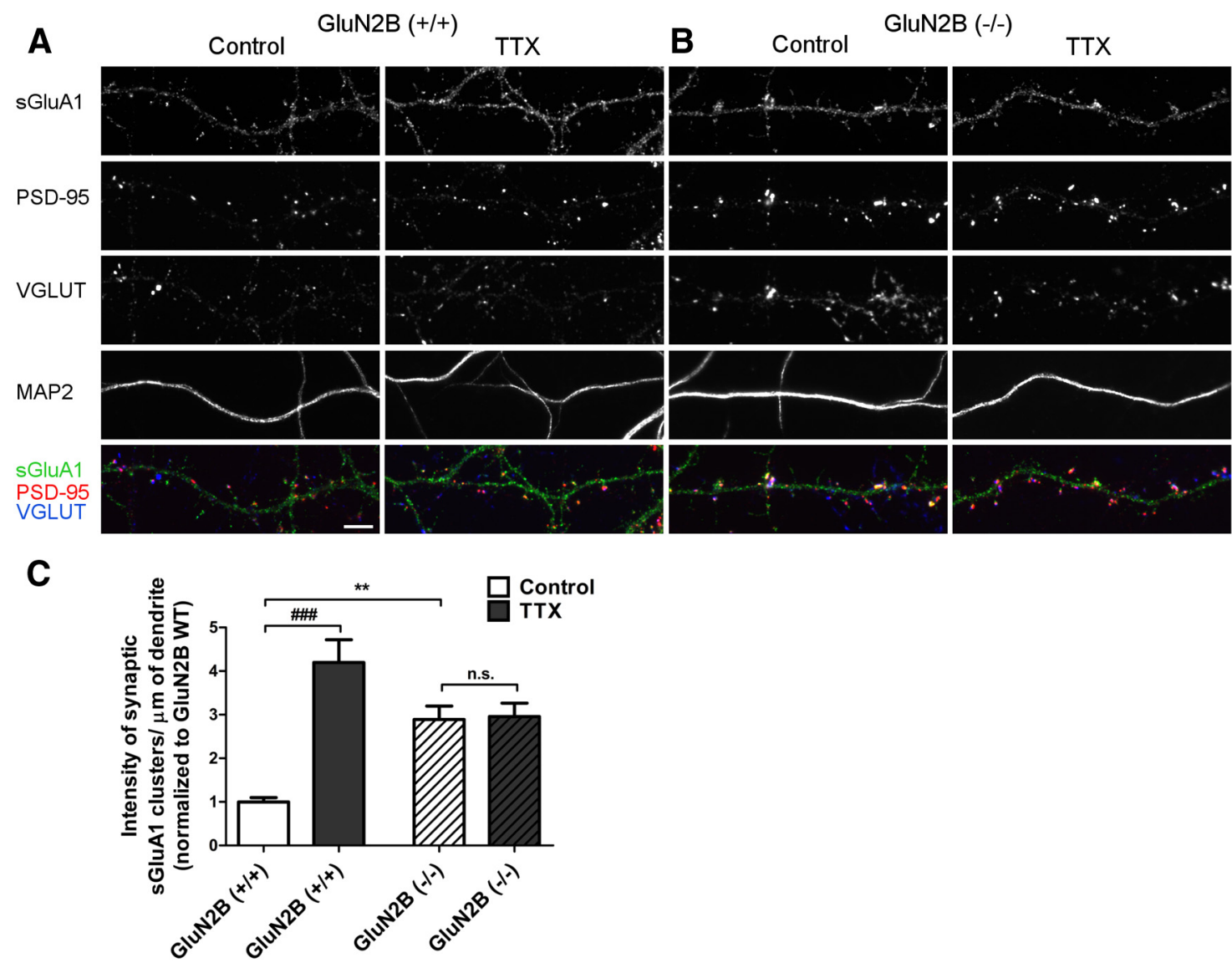

Figure 5. GluN2B is required for homeostatic synaptic scaling in response to blockade of neuronal activity. $A, B$, Low-density cortical cultures from wild-type and ${ }^{+/-}(A)$ and GluN2B ${ }^{-1-}$ mice (B) were incubated for $24 \mathrm{~h}$ at $14 \mathrm{DIV}$ with TTX $(2 \mu \mathrm{m})$ and immunostained for surface-GluA1 (live-staining, green merge). After fixation, cells were stained for PSD-95 (red merge), VGLUT (blue merge), and MAP2. Scale bar, $5 \mu \mathrm{m}$. C, The integrated intensity of the surface GluA1 (sGluA1) clusters per dendritic length was analyzed. Data are presented as mean $\pm S E M, n=37$ to 41 cells from two independent experiments. ${ }^{* *}$ Comparison between GluN2B ${ }^{+/+}$and GluN2B ${ }^{-/-}, p<0.01$; \#\#\#comparison between control and TTX conditions, $p<0.0001$, n.S., $p>0.05$, one-way ANOVA followed by Bonferroni's multiple-comparisons test.

be important for controlling this form of homeostatic plasticity. To model synaptic scaling, we treated low-density cortical neurons in culture for $24 \mathrm{~h}$ with the voltage-gated $\mathrm{Na}^{+}$channel blocker TTX to block action potential generation and quantified the surface AMPAR content by incubating live neurons with an antibody to the $\mathrm{N}$ terminus of the GluA1 subunit. As described previously (Louros et al., 2014), TTX significantly increased the total surface GluA1 cluster fluorescence intensity in wild-type neurons (Fig. 5A). Synaptic GluA1 was quantified as GluA1 clusters that colocalize with VGLUT and found to be also increased (Fig. $5 A, C ; p<0.001$, one-way ANOVA followed by Bonferroni's multiple-comparisons test). However, incubation with TTX did not significantly change synaptic GluA1 cluster intensity in GluN2B ${ }^{-l-}$ cortical neurons (Fig. $5 B, C$; $p>0.05$, one-way ANOVA followed by Bonferroni's multiplecomparisons test), suggesting that the mechanisms for scaling up synaptic AMPAR in response to chronic activity blockade are compromised in the absence of GluN2B.

\section{GluA1-AMPAR endocytosis is impaired in GluN2B ${ }^{-/-}$ hippocampal neurons}

One possibility is that decreased AMPAR endocytosis in neurons lacking the GluN2B subunit could underlie the synaptic accumulation of AMPAR subunits observed in these cultures (Fig. 4). To test this hypothesis, we used an antibody against the extracellular $\mathrm{N}$ terminus of GluA1 to perform an antibody feeding assay to detect endocytosed GluA1 in GluN2B ${ }^{-/-}$and wild-type hippocampal neurons after $30 \mathrm{~min}$ of incubation at $37^{\circ} \mathrm{C}$ (Fig. $6 A, B)$, a time point for which GluA1 intracellular accumulation has been shown to reach a plateau under basal conditions (Lin et al., 2000). In GluN2B ${ }^{+/+}$hippocampal neurons, we observed a significant increase (1.4-fold vs control, $p<0.001$, one-way ANOVA followed by Dunnett's multiple-comparisons test; Fig. $5 C$ ) in the internalization index of GluA1 (ratio between the intracellular fluorescence, permeabilized, and the total fluorescence, surface + permeabilized) after $30 \mathrm{~min}$ of incubation at $37^{\circ} \mathrm{C}$, which was blocked in the presence of Dynasore $(p>0.05$, one-way ANOVA followed by Dunnett's multiple-comparisons test vs wild-type control; Fig. 6C), a soluble dynamin inhibitor that acutely blocks clathrin-mediated endocytosis (Jaskolski et al., 2009). However, in GluN2B $^{-1-}$ neurons, the GluA1 internalization index was not changed after $30 \mathrm{~min}$ of incubation at $37^{\circ} \mathrm{C}(p>0.05$, one-way ANOVA followed by Dunnett's multiple-comparisons test vs GluN2B $^{-/-}$control; Fig. 6 C). These results indicate that GluA1 endocytosis is compromised in neurons lacking the GluN2B subunit.

Alterations in the proteome of postsynaptic densities isolated from GluN2B ${ }^{-/-}$neurons

The dramatic decrease in synaptic NMDARs (Fig. 1), as well as the increase in AMPAR synaptic content (Fig. 4) in the absence of GluN2B, suggest that this subunit contributes to building the synaptic scaffold that fine tunes synaptic composition and 


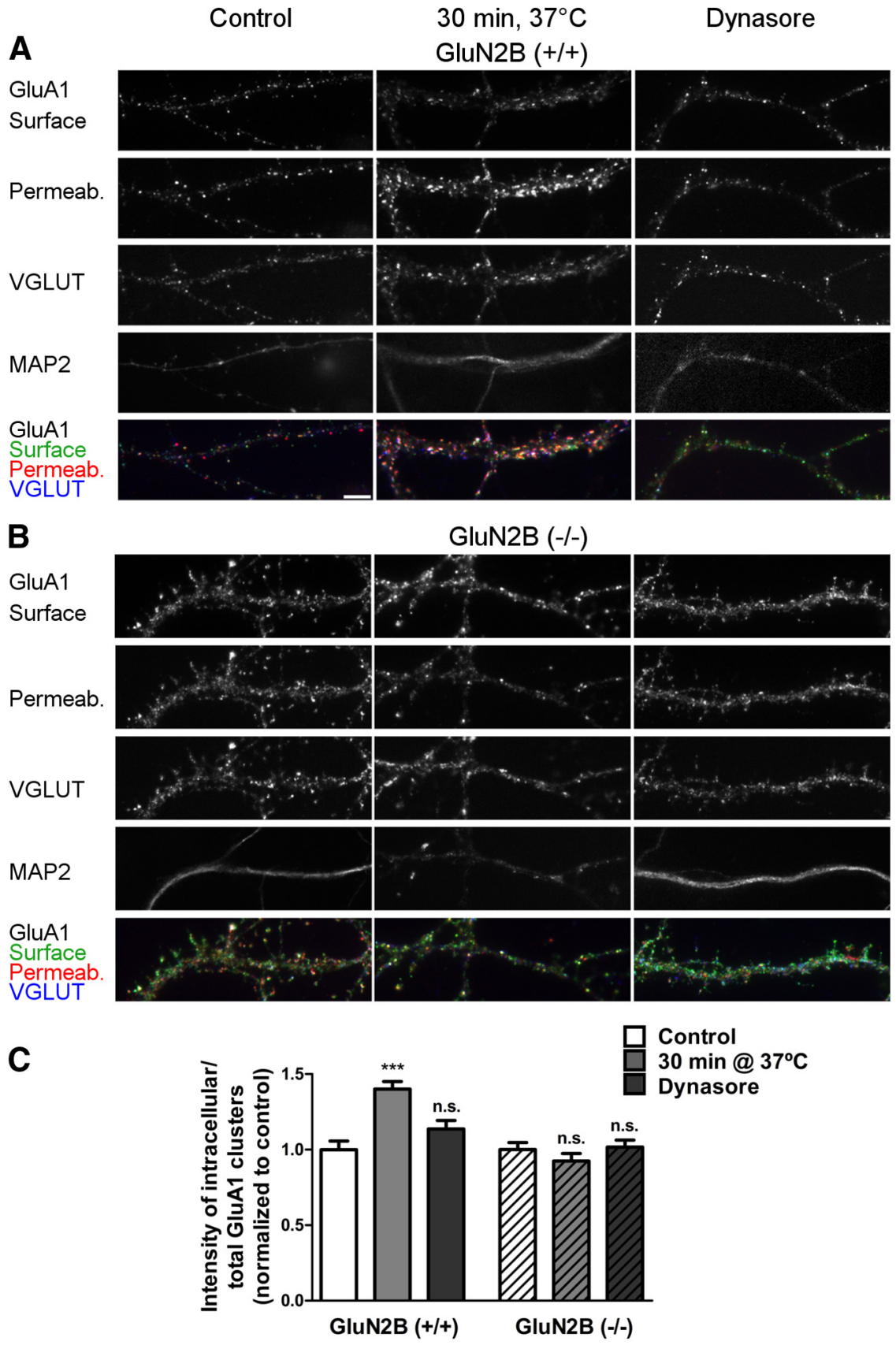

Figure 6. GluA1 internalization is impaired in hippocampal neurons lacking the GluN2B subunit. $A, B$, Low-density hippocampal cultures from wild-type and GluN2B ${ }^{+/-}(A)$ and GluN2B ${ }^{-1-}(B)$ mice were immunostained at 14 DIV for surface-GluA1 (live-staining) and incubated for $0 \mathrm{~min}$ (control) or $30 \mathrm{~min}$ at $37^{\circ} \mathrm{C}$ to induce endocytosis (antibody feeding assay) in the absence or in the presence of Dynasore $(120 \mu \mathrm{m})$. Neurons were fixed and stained for the surface remaining GluA1 clusters (surface, green merge) and then permeabilized and stained for the GluA1 clusters that were internalized (permeab., red merge). VGLUT (blue merge) and MAP2 staining were used as a presynaptic and a dendritic marker, respectively. Scale bar, $5 \mu \mathrm{m}$. $\mathbf{C}$, The integrated intensity of the surface and permeabilized GluA1 clusters per dendritic length were analyzed. The data are presented as the ratio of intracellular clusters (permeabilized) per total number of clusters (surface + permeabilized) corresponding to the internalization of the receptors. Data are presented as mean \pm SEM, $n=32$ cells from two independent experiments for time 0 (control) and time 30 min conditions and $n=16$ cells from one experiment for the Dynasore condition. ${ }^{* * *} p<0.0001$, n.s., $p>0.05$, compared with the respective control, one-way ANOVA followed by Dunnett's multiple-comparisons test.

strength. To test this possibility, we isolated PSDs from highdensity cortical neuron cultures (15 DIV) from GluN2B ${ }^{-I-}$ mice and from GluN2B ${ }^{+/+}$or GluN2B ${ }^{+/-}$littermates. At this age in culture, synapses have matured and dendritic spines have already acquired most of their elements (Rao et al., 1998). PSDs were successfully isolated from cultured cortical neurons and showed a selective enrichment in postsynaptic markers such as PSD-95, SynGAP, GluN1, GluN2A, and GluA1 and a decrease in the content of the presynaptic protein synaptophysin (Fig. $7 A, B$ ). Interestingly, we observed a reduction in the total protein content of PSDs isolated from $\mathrm{GluN}_{2} \mathrm{~B}^{-1-}$ neurons compared with PSDs isolated from control neurons (to $42.86 \pm 10.7 \%$ the total amount of protein in control PSDs, $p<0.01, t$ test). Because the PSD purification experiments were done in parallel and from the same initial number of cells ( $\sim 38 \mathrm{M}$ per genotype), the difference in the PSD protein yield between control and GluN2B ${ }^{-1-}$ neurons suggests that the GluN2B subunit is important for maintaining the cohesion of the PSD macromolecular complex.

Three replicas of the PSD samples isolated from GluN2B ${ }^{+/+}$and two from GluN2B $^{+/-}$cortical neurons were compared with three replicas of PSDs isolated from GluN2B ${ }^{-1-}$ cortical neurons by quantitative mass spectrometry (Fig. 7C). The chosen method takes advantage of labeling peptides with an isobaric peptide tag for relative and absolute quantification (iTRAQ), in conjunction with tandem liquid chromatography-MS/MS for protein characterization and quantification. The iTRAQ method is based on the differential covalent labeling of digested peptides with one of eight specific iTRAQ reagents. These are composed of a peptide reactive group that labels the primary amines of peptides, a reporter group, each with a different mass $(113,114,115,116$, $117,118,119$, and $121 \mathrm{Da}$ ), and a balance group (Aggarwal et al., 2005). The iTRAQ reagents are indistinguishable by mass, due to the balance group, giving rise to single peptide peaks in MS scans that are used for protein identification. When iTRAQ-tagged peptides are subjected to MS/MS analysis, the balance groups are released, giving rise to reporter ions that provide quantitative information. The peak areas of the resultant reporter ions can be used to calculate the relative abundance of a given peptide. The iTRAQ ratios (sample vs GluN2B ${ }^{+/+}$ PSDs labeled with the 113 reporter group) were used to determine the concentration ratios for the identified proteins in the GluN2B ${ }^{-1-}$ versus control PSDs. We were able to indentify 1168 proteins in the PSD fractions using at least two peptides with $\geq 99 \%$ confidence for each protein from 20,007 distinct peptides; from these, 790 proteins could be relatively quantified (unused value at least four, data not shown).

Gene ontology analysis using the GoMiner functional annotation tool (Zeeberg et al., 2003) showed that proteins identified 
A

B
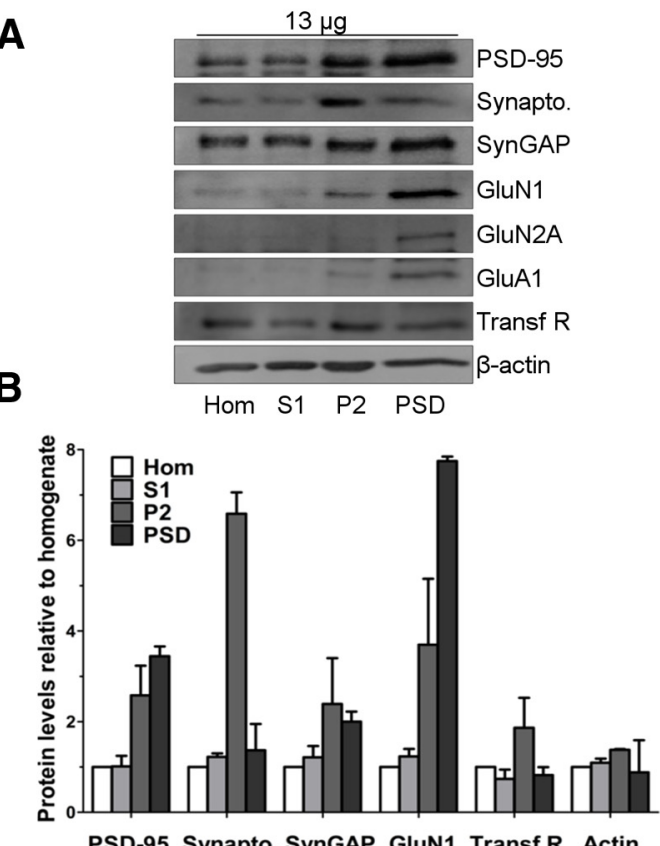

C

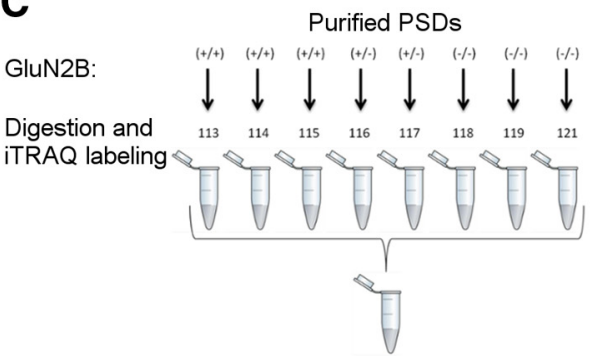

Peptide fractionation by 2-dimensional liquid chromatography MALDI MS/MS analysis

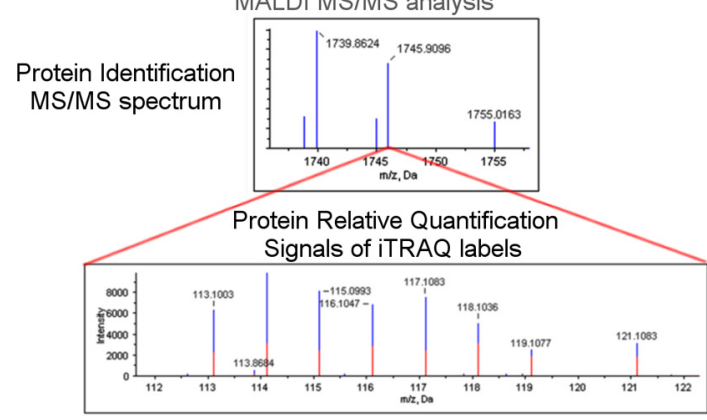

D

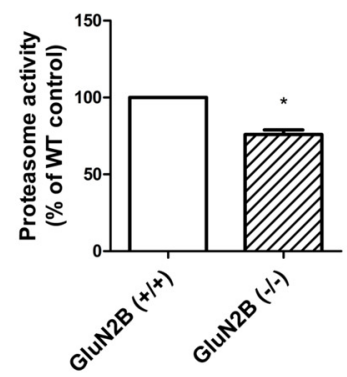

Figure 7. Proteomic analysis of the PSD fraction of GluN2B ${ }^{-1-}$ cortical neurons. $A$, PSDs were successfully purified from high-density rat cortical cultures (14-15 DIV). Western blot for markers of the presynaptic (Synaptophysin) and postsynaptic fractions (PSD-95, SynGAP, NMDAR receptor subunits GluN1 and GluN2A, and AMPAR subunit GluA1) validated PSD isolation of PSDs. Transferrin receptor (Transf $\mathrm{R}$ ) and $\beta$-actin were used as controls. Hom, Homogenate; $S 1$, non-nuclear fraction; $P 2$ crude synaptosomes. Equal amounts $(13 \mu \mathrm{g})$ of each fraction were applied. B, PSD-localized proteins (PSD-95, GluN1, SynGAP) are increased relative to the homogenate in the PSD fraction, whereas presynaptic synaptophysin (Synapto.) or the trans in the PSDs include cell surface receptors, scaffold proteins, motor proteins, GTPases and their regulators, proteins involved in the traffic to and from the membrane, kinases and phosphatases, proteins associated with metabolic processes, cytoskeleton components, chaperons, and adhesion molecules, among others, similar to what has been described in the PSDs isolated from rat brain (for review, see Sheng and Hoogenraad, 2007). Our wild-type PSD protein list contains 128 proteins annotated as synaptic proteins, which is significantly more than the 55 and 44 proteins detected in previous studies (Collins et al., 2006; Zhang et al., 2012), and indicates a comprehensive analysis of the PSD composition in our study. We looked for the detection in the isolated PSD fractions from wild-type mice cortical neurons of proteins previously identified in other proteomic studies that characterized the proteome of PSDs isolated from brain as core components of PSDs (Husi et al., 2000; Cheng et al., 2006; Dosemeci et al., 2007). We found 43 PSD core proteins in the PSDs isolated from cortical neuronal cultures, all of which were also present in the PSDs isolated from GluN2B ${ }^{-1-}$ cortical neurons. Within this selection of core proteins of the PSD, we found a small number of proteins that were significantly changed in PSDs isolated from GluN2B ${ }^{-1-}$ neurons, namely the GluN1 NMDAR subunit, which is highly reduced ( $p<0.001, t$ test), and glutamine synthetase, which is increased ( $p<0.05, t$ test), in the PSDs of GluN2B $^{-1-}$ cortical neurons compared with control (Table 1). These results indicate that the main components of the PSD are not dramatically changed in GluN2B ${ }^{-1-}$ neurons compared with wild-type neurons.

Quantitative analysis of the protein content of the isolated PSDs revealed altered levels in GluN2 $\mathrm{B}^{-1-}$ PSDs for 32 proteins involved in a diversity of signaling processes (Table 1). Several components of the ubiquitin proteasome system (UPS) were altered in the PSDs isolated from neurons lacking GluN2B. The proteasome subunits Psmb1 and Psmb2 were significantly decreased $(p<0.05$; Table 1$)$ and several of the $\alpha$ subunits of the proteasome (Psma1, 3, 6, 7) were also decreased in PSDs isolated from GluN2B ${ }^{-1-}$ compared with control PSDs, even though their decrease did not reach statistical significance. In addition, the E3 ubiquitin-ligase Ubr4, which recognizes N-degrons (proteins containing destabilizing $\mathrm{N}$-terminal residues) for ubiquitindependent proteolysis (Tasaki et al., 2005), was decreased ( $p<$ 0.05; Table 1), whereas the deubiquitinating enzyme Usp31 and the ubiquitin-conjugating enzyme Ubal were increased $(p<$ 0.001 and $p<0.05$, respectively; Table 1 ). These results support the hypothesis that the UPS is altered in the PSDs of GluN2B ${ }^{-/-}$ cortical neurons.

\footnotetext{
$\leftarrow$

membrane receptor of transferrin are decreased compared with the $\mathrm{P} 2$ fraction, consistent with their absence or low expression, respectively, at the PSD. Actin levels did not change in any of the fractions analyzed. Data are presented as mean \pm SEM from two independent experiments. C, Setup of the 8-plex iTRAQ experiments. Isolated PSDs from GluN2B ${ }^{+/+}, \mathrm{GluN} \mathrm{B}^{+/-}$, and GluN2B ${ }^{-1-}$ cortical neurons, $10 \mu \mathrm{g}$ each, were digested with trypsin and samples (three wild-types, two heterozygous, and three knock-outs) were tagged with a set of 8-plex iTRAO reagents. Peptides were pooled together and fractionated by $2 \mathrm{D}$ liquid chromatography and subject to tandem mass spectrometric analysis. After using peptides for protein identification, the individual contribution of each sample to each peptide can be measured by the intensity of the reporter ion peaks and used for relative quantification. Example spectra correspond to one of the GluN1 peptides identified in the PSD preparations. $\boldsymbol{D}$, Chymotrypsin-like proteasome activity was measure in protein extracts from GluN2B $\mathrm{B}^{+/+}$and GluN2B $\mathrm{B}^{-1-}$ cortical neurons. Proteasome activity is significantly decreased $(p<0.05)$ in GluN2B ${ }^{-/-}$neurons compared with control neurons. The control proteasome activity, determined in GluN2B ${ }^{+/+}$neurons, was set to $100 \%$. Data are presented as mean \pm SEM from three independent experiments. ${ }^{*} p<0.05$, paired $t$ test.
} 
Table 1. Proteins of the PSD that displayed significant changes in abundance in PSDs isolated from GluN2B ${ }^{-/-}$cortical neurons compared with control neurons

\begin{tabular}{|c|c|c|c|c|c|c|}
\hline Protein name & Gene symbol & Accession no. & $\begin{array}{l}\text { Coverage of the } \\
\text { protein (\%) }\end{array}$ & $\begin{array}{l}\text { No. of peptides } \\
(\mathrm{Cl} \geq 95 \%)\end{array}$ & $\begin{array}{l}\text { [Control: reference] } \\
\pm \text { SEM }\end{array}$ & $\begin{array}{l}{\left[\text { GluN2B } \mathrm{B}^{-l-}: \text { reference }\right]} \\
\pm \mathrm{SEM}\end{array}$ \\
\hline \multicolumn{7}{|l|}{ Core proteins } \\
\hline GluN1 & Grin1 & IPI:IPI00751834.1 & 18.67 & 2 & $0.847 \pm 0.187$ & $0.322 \pm 0.117$ \\
\hline Glutamine synthetase & Glul & IPI:IPI00626790.3 & 45.58 & 8 & $0.750 \pm 0.186$ & $1.422 \pm 0.192$ \\
\hline \multicolumn{7}{|l|}{ Actin cytoskeleton } \\
\hline Actin-related protein 3 & Actr3 & IPI:IPI00115627.4 & 37.59 & 9 & $0.879 \pm 0.089$ & $0.464 \pm 0.021$ \\
\hline Actin filament-associated protein 1 & Afap1 & IPI:IPI00467327.4 & 22.33 & 2 & $1.057 \pm 0.064$ & $0.697 \pm 0.049$ \\
\hline Profilin-2 & Pfn2 & IPI:IPI00845675.1 & 35.12 & 4 & $1.092 \pm 0.064$ & $1.399 \pm 0.044$ \\
\hline \multicolumn{7}{|l|}{ GTPases } \\
\hline RAB5C member RAS oncogene family & Rab5c & IPI:IPI00404579.1 & 49.5 & 3 & $1.156 \pm 0.063$ & $1.542 \pm 0.143$ \\
\hline Ras-related protein Rab-10 & Rab10 & IPI:IPI00130118.1 & 78.13 & 6 & $0.960 \pm 0.110$ & $1.752 \pm 0.220$ \\
\hline $\begin{array}{l}\text { Guanine nucleotide-binding protein subunit } \\
\text { beta- } 5\end{array}$ & Gnb5 & IPI:IPI00127930.1 & 54.93 & 7 & $0.825 \pm 0.049$ & $0.408 \pm 0.045$ \\
\hline \multicolumn{7}{|l|}{ Cell adhesion molecules } \\
\hline $\begin{array}{l}\text { Cell cycle exit and neuronal differentiation } \\
\text { protein } 1\end{array}$ & Cend1 & IPI:IPI00122826.1 & 42.15 & 2 & $1.102 \pm 0.092$ & $0.196 \pm 0.079$ \\
\hline Neurexin-2 & Nrxn2 & IPI:IPI00918148.1 & 36.58 & 7 & $0.919 \pm 0.054$ & $0.461 \pm 0.049$ \\
\hline Ephrin type-A receptor 4 precursor & Epha4 & IPI:IPI00337992.1 & 21.37 & 12 & $0.815 \pm 0.073$ & $0.569 \pm 0.052$ \\
\hline Neurofascin isoform 2 precursor & Nfasc & IPI:IPI00930898.1 & 29.03 & 4 & $1.028 \pm 0.037$ & $1.156 \pm 0.030$ \\
\hline \multicolumn{7}{|l|}{ Kinases } \\
\hline Tyrosine-protein kinase Fyn & Fyn & IPI:IPI00762435.2 & 48.92 & 11 & $0.956 \pm 0.051$ & $0.703 \pm 0.042$ \\
\hline $\begin{array}{l}\text { cAMP-dependent protein kinase catalytic } \\
\text { subunit alpha }\end{array}$ & Prkaca & IPI:IPI00230005.3 & 42.31 & 5 & $0.756 \pm 0.102$ & $1.290 \pm 0.144$ \\
\hline \multicolumn{7}{|l|}{ UPS } \\
\hline E3 ubiquitin-protein ligase UBR4 & Ubr4 & IPI:IPI00845523.1 & 72.29 & 10 & $0.669 \pm 0.105$ & $0.317 \pm 0.069$ \\
\hline Proteasome subunit beta type-1 & Psmb1 & IPI:IPI00113845.1 & 23.56 & 5 & $0.801 \pm 0.074$ & $0.459 \pm 0.089$ \\
\hline Proteasome subunit beta type- 2 & Psmb2 & IPI:IPI00128945.1 & 27.8 & 8 & $0.730 \pm 0.092$ & $0.434 \pm 0.039$ \\
\hline Ubiquitin-like modifier-activating enzyme 1 & Uba1 & IPI:IPI00123313.1 & 36.45 & 11 & $1.360 \pm 0.116$ & $1.788 \pm 0.057$ \\
\hline Ubiquitin specific protease 31 & Usp31 & IPI:IPI00762403.1 & 30.03 & 2 & $1.281 \pm 0.393$ & $8.085 \pm 1.303$ \\
\hline \multicolumn{7}{|l|}{ Translation and protein folding } \\
\hline T-complex protein 1 subunit delta & Cct4 & IPI:IPI00116277.3 & 41.96 & 16 & $0.879 \pm 0.054$ & $0.647 \pm 0.021$ \\
\hline T-complex protein 1 subunit zeta & Cct6a & IPI:IPI00116281.3 & 21.54 & 17 & $0.871 \pm 0.040$ & $0.747 \pm 0.002$ \\
\hline $\begin{array}{l}\text { Heat shock protein } 105 \text { kDa. Isoform HSP105- } \\
\text { alpha }\end{array}$ & Hsph1 & IPI:IPI00123802.5 & 44 & 3 & $0.684 \pm 0.133$ & $1.389 \pm 0.151$ \\
\hline 605 ribosomal protein $\mathrm{L} 8$ & Rpl8 & IPI:IPI00137787.3 & 46.59 & 8 & $0.976 \pm 0.044$ & $0.644 \pm 0.078$ \\
\hline \multicolumn{7}{|l|}{ Metabolism } \\
\hline Atp8a1 protein & Atp8a1 & IPI:IPI00466422.2 & 67.16 & 4 & $1.168 \pm 0.086$ & $0.739 \pm 0.083$ \\
\hline Prdx5 protein & Prdx5 & IPI:IPI00475031.1 & 44.81 & 2 & $0.969 \pm 0.042$ & $1.259 \pm 0.018$ \\
\hline Peroxiredoxin-1 & $\operatorname{Prdx} 1$ & IPI:IPI00121788.1 & 36.03 & 9 & $0.902 \pm 0.107$ & $1.272 \pm 0.047$ \\
\hline $\begin{array}{l}\text { V-type proton ATPase } 16 \mathrm{kDa} \text { proteolipid } \\
\text { subunit }\end{array}$ & Atp6r0c & IPI:IPI00138378.4 & 41.64 & 6 & $0.773 \pm 0.084$ & $1.070 \pm 0.089$ \\
\hline Fructose-bisphosphate aldolase A & Aldoa & IPI:IPI00856379.1 & 53 & 38 & $0.721 \pm 0.123$ & $0.232 \pm 0.089$ \\
\hline Fatty acid-binding protein & Fabp7 & IPI:IPI00227585.6 & 58.33 & 3 & $1.040 \pm 0.073$ & $1.637 \pm 0.248$ \\
\hline \multicolumn{7}{|l|}{ Other } \\
\hline Calmodulin & Calm1-3 & IPI:IPI00761696.2 & 51.58 & 15 & $0.991 \pm 0.099$ & $0.469 \pm 0.106$ \\
\hline Phosphofurin acidic cluster sorting protein 1 & Pacs1 & IPI:IPI00321922.2 & 27.97 & 7 & $1.108 \pm 0.075$ & $1.538 \pm 0.047$ \\
\hline Rps6-ps1 Uncharacterized protein & Rps6-ps1 & IPI:IPI00108454.2 & 21.93 & 5 & $1.098 \pm 0.030$ & $0.876 \pm 0.064$ \\
\hline
\end{tabular}

Cl, Confidence interval.

To evaluate whether the proteasome activity is altered in GluN2B $^{-1-}$ neurons, we assessed the chymotrypsin-like proteasome activity in cortical neuronal extracts using the fluorogenic substrate Suc-LLVY-AMC. The proteasome activity was reduced by $24 \pm 2.96 \%$ in GluN2B ${ }^{-1-}$ cortical neurons relative to GluN2B ${ }^{+/+}$neurons $(p<0.05$ paired $t$ test; Fig. $7 D)$.

\section{Regulation of synaptic GluA1-AMPAR accumulation by the proteasome}

The UPS is an important modulator of synaptic function and plasticity (Bingol and Sheng, 2011). In cultured neurons, blocking polyubiquitination or the proteasome activity prevents agonist-induced internalization of AMPARs (Patrick et al., 2003), suggesting that proteasomal activity is required to degrade proteins and therefore allow receptor internalization. We there- fore reasoned that if the downregulation of the proteasome at synapses in GluN2B lacking neurons accounts for increased AMPAR synaptic levels, then we should be able to rescue normal AMPAR levels by activating the remaining proteasome in GluN2B $^{-1-}$ neurons. To test this possibility we incubated 13 DIV hippocampal neurons with an enhancer of the proteasome activity, the small-molecule inhibitor of Usp14, IU1-47 [1-[1-(4-fluorophenyl)-2,5-dimethylpyrrol-3-yl]-2-pyrrolidin-1-ylethanone] (Lee et al., 2010). Usp14 is a proteasome-associated deubiquitinating enzyme that can inhibit the degradation of ubiquitin-protein conjugates by trimming ubiquitin chains before commitment to substrate degradation, thus functioning as an inhibitor of the proteasome (Lee et al., 2010). By inhibiting Usp 14 activity, IU1-47 activates the proteasome. Twenty-four hours after the incubation with IU1-47, hippocampal neurons were fixed and labeled for the GluA1 or GluA2 
A

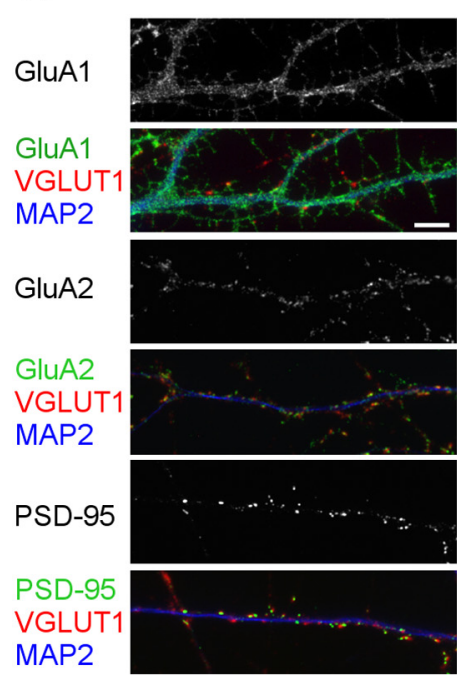

B

GluA1

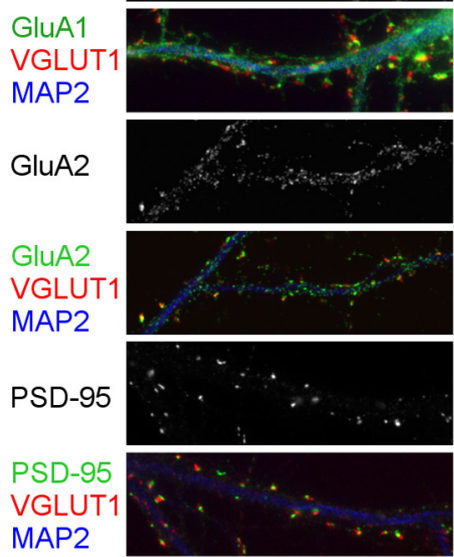

c

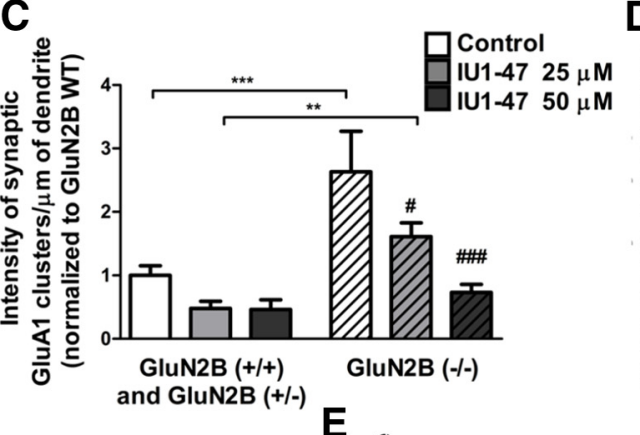

E
Control

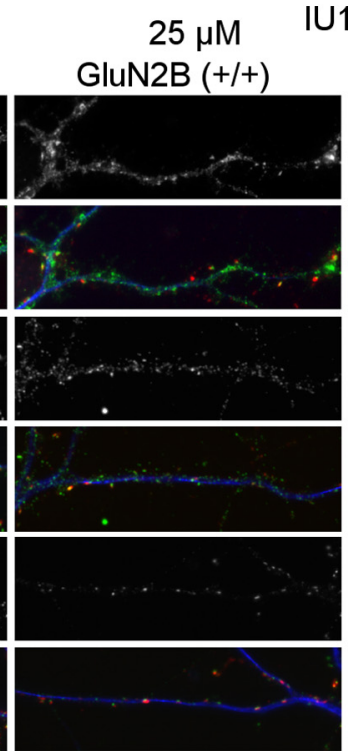

GluN2B (-/-)
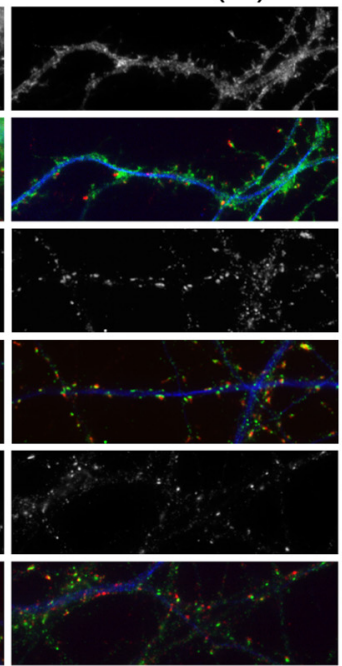

D
$1-47 \quad 50 \mu \mathrm{M}$
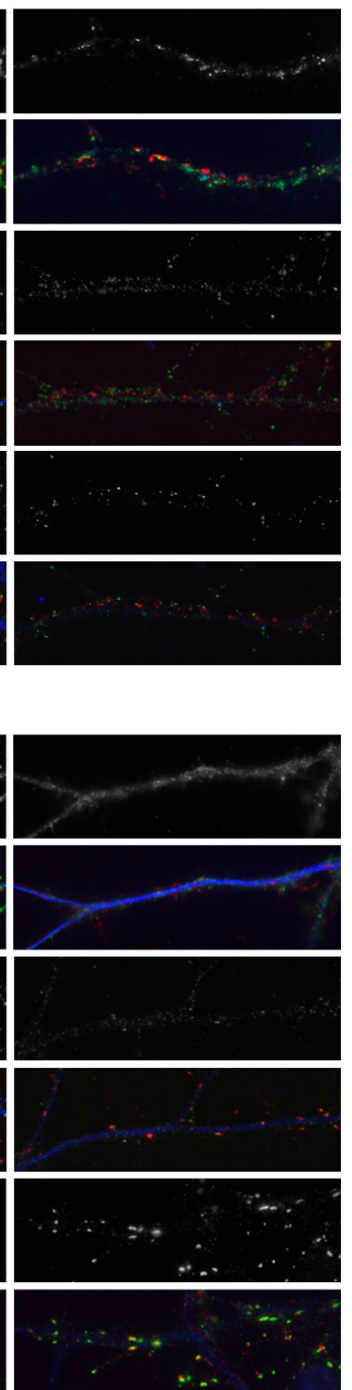

흔

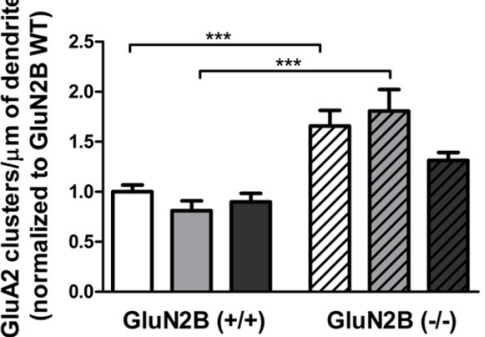

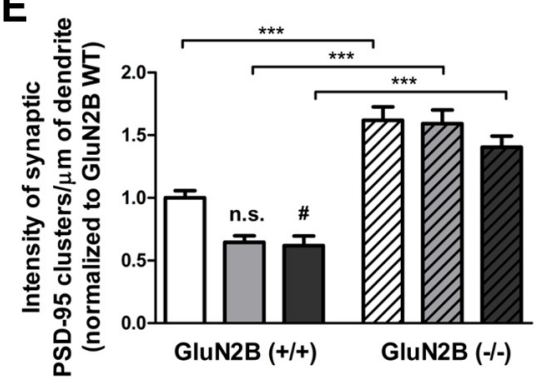

subunits, PSD-95, the presynaptic marker VGLUT1, and the dendritic maker MAP2 (Fig. $8 A, B$ ). No significant changes in VGLUT1 clustering were found when neurons were incubated with IU1-47 ( $p>0.05$, one-way ANOVA followed by Bonferroni's multiple-comparisons test). However, we observed that, upon activation of the proteasome, synaptic (VGLUT1-colocalized) GluA1 clustering in GluN2B ${ }^{-1-}$ neurons was significantly decreased in an IU1-47 concentration-dependent manner $(p<$ 0.05 for $25 \mu \mathrm{M}, p<0.001$ for $50 \mu \mathrm{M}$, oneway ANOVA followed by Bonferroni's multiple-comparisons test vs GluN2B ${ }^{-1-}$ control; Fig. 8C). Indeed, incubation with $50 \mu \mathrm{M}$ IU1-47 rescued GluA1 clusters levels in GluN2B $^{-/-}$neurons to GluN2B ${ }^{+/+}$levels $(p>0.05$, one-way ANOVA followed by Bonferroni's multiple-comparisons test vs GluN2B wild-type $50 \mu \mathrm{M}$; Fig. $8 C$ ), whereas the effect of IU1-47 on GluA1 synaptic clusters in GluN2B ${ }^{+/+}$hippocampal neurons was not statistically significant $(p>0.05$, one-way ANOVA followed by Bonferroni's multiple-comparisons test; Fig. 8C). Activation of the proteasome with IU1-47 also decreased the GluA2 synaptic clusters in GluN2B $^{-1-}$ neurons (Fig. $8 D$ ), partially rescuing GluA2 levels to those observed in wild-type neurons. However, the limiting amount of synaptic proteasome in GluN2B $^{-1-}$ neurons did not allow rescuing the levels for all proteins using IU1-47. We observed that the intensity of VGLUT-colocalized PSD-95 clusters was increased in GluN2B ${ }^{-1-}$ neurons compared with wild-type (Fig. $8 A, B, E$ ) despite the decrease in synapse number in

Figure 8. AMPAR synaptic expression is restored to control levels in GluN2B ${ }^{-1-}$ hippocampal neurons upon activation of the proteasome. $A, B$, Low-density hippocampal cultures from control $\left(\boldsymbol{A} ; \mathrm{GluN}_{2} \mathrm{~B}^{+/+}\right.$and GluN2B $\left.{ }^{+/-}\right)$and GluN2B $\mathrm{B}^{-/-}$ $(B)$ mice were fixed at 14 DIV and stained for the AMPAR subunits GluA1 or GluA2 (green, merge), the excitatory postsynaptic marker PSD-95 (green, merge), and the presynaptic marker VGLUT (red, merge). MAP2 staining was used as a dendritic marker (blue, merge). Scale bar, $5 \mu \mathrm{m}$. Hippocampal neurons were incubated with 25 or $50 \mu \mathrm{M}$ IU1-47 for $24 \mathrm{~h}$ before neuronal fixation and staining. $\boldsymbol{C}-\boldsymbol{E}$, The integrated intensity of the synaptic (apposed to VGLUT) GluA1 (C), GluA2 (D)or PSD-95 (E) clusters per dendritic length was analyzed. Data are presented as mean \pm SEM, $n=29-48$ cells from three independent experiments for GluA1 clustering; $n=$ 39-60 cells from two or three independent experiments for GluA2 clustering; $n=55-76$ from three or four independent experiments for PSD-95. ${ }^{* *} p<0.001$ and ${ }^{* *} p<0.01$ for comparison between genotypes; \#p $<0.05$ and \#\#\# $<$ 0.0001 for comparison between IU1-47-treated and control neurons for each genotype, one-way ANOVA, followed by Bonferroni's multiple-comparisons test. 
these neurons (Gambrill and Barria, 2011). Activation of the proteasome with IU1-47 decreased synaptic PSD-95 levels in wildtype neurons (Fig. $8 A, E$ ), in agreement with PSD-95 degradation in the proteasome (Colledge et al., 2003), but not in GluN2B ${ }^{-1-}$ neurons (Fig. $8 B, E$ ). This suggests that the remaining synaptic proteasome in GluN2B ${ }^{-1-}$ neurons could not efficiently degrade PSD-95 even upon activation with IU1-47. Our results point to a role of the proteasome in restricting synaptic AMPARs in an NMDAR-dependent way.

Finally, we tested whether activation of the proteasome in GluN2B $^{-1-}$ neurons can recover AMPAR endocytosis. Wildtype or GluN2B ${ }^{-1-}$ hippocampal neurons were incubated for 30 min with IU1-47 before the antibody-feeding protocol was used to detect endocytosed GluA1 after $30 \mathrm{~min}$ of incubation at $37^{\circ} \mathrm{C}$ (Fig. 9A,B). Interestingly, GluA1 endocytosis was increased in GluN2B ${ }^{-1-}$ neurons incubated with IU1-47 and became similar to the GluA1 endocytosis levels observed in wild-type neurons $(p<0.001$, one-way ANOVA followed by Dunnett's multiplecomparisons test vs the respective controls; Fig. 9 C).

\section{Discussion}

In this study, we took advantage of GluN2A $\mathrm{A}^{-/-}$and GluN2B ${ }^{-/-}$ neuronal cultures to uncover the differential role of GluN2 subunits in the synaptic targeting of NMDARs. We observed that, whereas synaptic clustering of NMDARs is dramatically decreased in GluN2B ${ }^{-1-}$ hippocampal neurons, it is unaffected in GluN2A ${ }^{-1-}$ neurons (Figs. $1 ; 2$ ), suggesting a specific role for the GluN2B subunit in building a platform for the synaptic targeting/ anchoring of NMDARs. Our data are in good agreement with electrophysiology studies showing a loss of NMDAR-mediated currents in neurons lacking GluN2B (Kutsuwada et al., 1996; Akashi et al., 2009). The synaptic incorporation of GluN2A-containing receptors is activity dependent, whereas GluN2B-containing receptors are delivered at synaptic sites in a constitutive manner independently of receptor-mediated activity (Barria and Malinow, 2002). This could explain in part the absence of synaptic GluN2A-containing NMDARs in GluN2B ${ }^{-1-}$ neurons despite the significant expression of GluN2A in these neurons at 15 DIV (Fig. $3 B, D$ ).

We further demonstrate that chronic NMDAR blockade, which elicits homeostatic upregulation of synaptic NMDARs in hippocampal neurons (Rao and Craig, 1997), promotes the synaptic clustering of NMDARs in wild-type or GluN2A ${ }^{-1-}$ mouse hippocampal cultures (Fig. 1;2) but fails to change GluN1 clustering in GluN2B ${ }^{-/-}$neurons (Fig. $1 C$ ), indicating that GluN2B is essential for the mechanisms that regulate NMDAR traffic homeostatically.

In cortical GluN2B ${ }^{-/-}$neurons, total protein levels of GluN1 and GluN2A are significantly decreased (Fig. $3 A-D$ ) in a transcription-independent manner (Figs. $3 E, F$ ), suggesting that GluN2B-containing NMDARs are required to maintain a stable pool of NMDARs. The decrease in GluN1 levels in the absence of GluN2B is in agreement with previous reports (Kim et al., 2005; Akashi et al., 2009; Brigman et al., 2010; but see also Hall et al., 2007) and could be secondary to the loss of GluN2B because unassembled GluN1 subunits are rapidly degraded (Huh and Wenthold, 1999). However, we also observed a transcriptionindependent decrease in the GluN2A in GluN2B ${ }^{-1-}$ neurons (Fig. $3 B, D$ ). Previous reports on the GluN2A expression in the absence of GluN2B are contradictory, with some studies reporting a decrease in GluN2A (Kim et al., 2005; Akashi et al., 2009) and others reporting no changes (Hall et al., 2007; von Engelhardt et al., 2008; Brigman et al., 2010). Our data are consistent with the idea that GluN1/GluN2A NMDARs are destabilized in the ab- sence of GluN2B-containing NMDARs, raising the possibility that inappropriate synaptic targeting and/or anchoring of GluN1/GluN2A-NMDARs in the absence of GluN2B leads to receptor removal by lateral diffusion or endocytosis and receptor degradation.

Previous studies showed an increase in AMPAR-mediated currents in the absence of GluN2B (Adesnik et al., 2008; Hall and Ghosh, 2008). We report increased synaptic expression of GluA1 and GluA2 AMPAR subunits in GluN2B ${ }^{-1-}$ neurons (Fig. 4), in agreement with the idea that, under basal activity, GluN2Bcontaining NMDARs act to suppress the synaptic incorporation of AMPARs. Enhancement of AMPAR synaptic currents after NMDAR ablation requires the GluA2 subunit (Lu et al., 2011); accordingly, both GluA1 and GluA2 synaptic levels are increased in GluN2B ${ }^{-/-}$hippocampal neurons (Fig. 4D-G).

Despite the strong evidence that NMDAR signaling under basal conditions restricts AMPAR synaptic incorporation, little is known about the underlying mechanisms. It was previously proposed that GluN2B-NMDARs inhibit the surface expression of GluA1-containing AMPARs by coupling to the inhibition of the Ras-ERK pathway and therefore to the inhibition of the surface expression of GluA1 (Kim et al., 2005). The functional coupling of SynGAP, a RasGAP, to GluN2B correlates with the GluN2Bmediated inhibition of the Ras-ERK pathway. Indeed, we found a significant decrease in the intensity of synaptic (VGLUTcolocalized) SynGAP clusters in hippocampal GluN2B ${ }^{-1-}$ neurons to $81.58 \pm 8.65 \%$ compared with wild-type $(p<0.01$ Mann-Whitney test, data not shown), which could contribute to increased AMPAR synaptic expression because decreased SynGAP expression results in enhancement of AMPAR-mediated synaptic transmission (Rumbaugh et al., 2006; Wang et al., 2013). In addition, we found that homeostatic upscaling of AMPA receptors upon chronic activity suppression is blocked in GluN2B ${ }^{-/-}$neurons (Fig. 5). Given the increased synaptic levels of GluA1 and GluA2 in the knock-out neurons (Fig. 4), we propose that scaling up may be partially occluded in these neurons. Nevertheless, a previous report showed intact synaptic scaling in response to chronic TTX treatment in GluN2B ${ }^{-1-}$ neurons detected by changes in AMPAR-mediated mEPSCs (Wang et al., 2011).

We present evidence that GluA1-AMPAR endocytosis is impaired in hippocampal neurons lacking GluN2B (Fig. 6), which contributes to upregulated synaptic AMPAR levels. To further investigate changes in the synaptic scaffold of GluN2B ${ }^{-/-}$neurons that could underlie altered AMPAR synaptic expression, we used a quantitative approach to compare the proteomes of PSDs isolated from GluN2B ${ }^{-/-}$versus control cortical neurons (Table 1). One of the differentially expressed protein categories includes several proteasome subunits that were found to be decreased in GluN2B $^{-1-}$ PSDs. In fact, several recent studies show that the UPS is important for the development, maintenance, and plasticity of synapses (for review, see Bingol and Sheng, 2011). Hebbian forms of synaptic plasticity rely on protein degradation at the proteasome (Fonseca et al., 2006; Dong et al., 2008; Santos et al., 2015) and long-term homeostatic plasticity controls the composition of synapses via the UPS (Ehlers, 2003). Key synaptic proteins such as PSD-95, Shank, SAPAP, AKAP, and GRIP-1 have been shown to be regulated by proteasome-dependent turnover (Colledge et al., 2003; Ehlers, 2003; Lussier et al., 2011) and the proteasome is required for AMPAR endocytosis (Patrick et al., 2003).

The GluN2B-mediated regulation of AMPARs was found to require the binding of CaMKII to GluN2B because the increase in the synaptic level of AMPARs in the absence of GluN2B was 


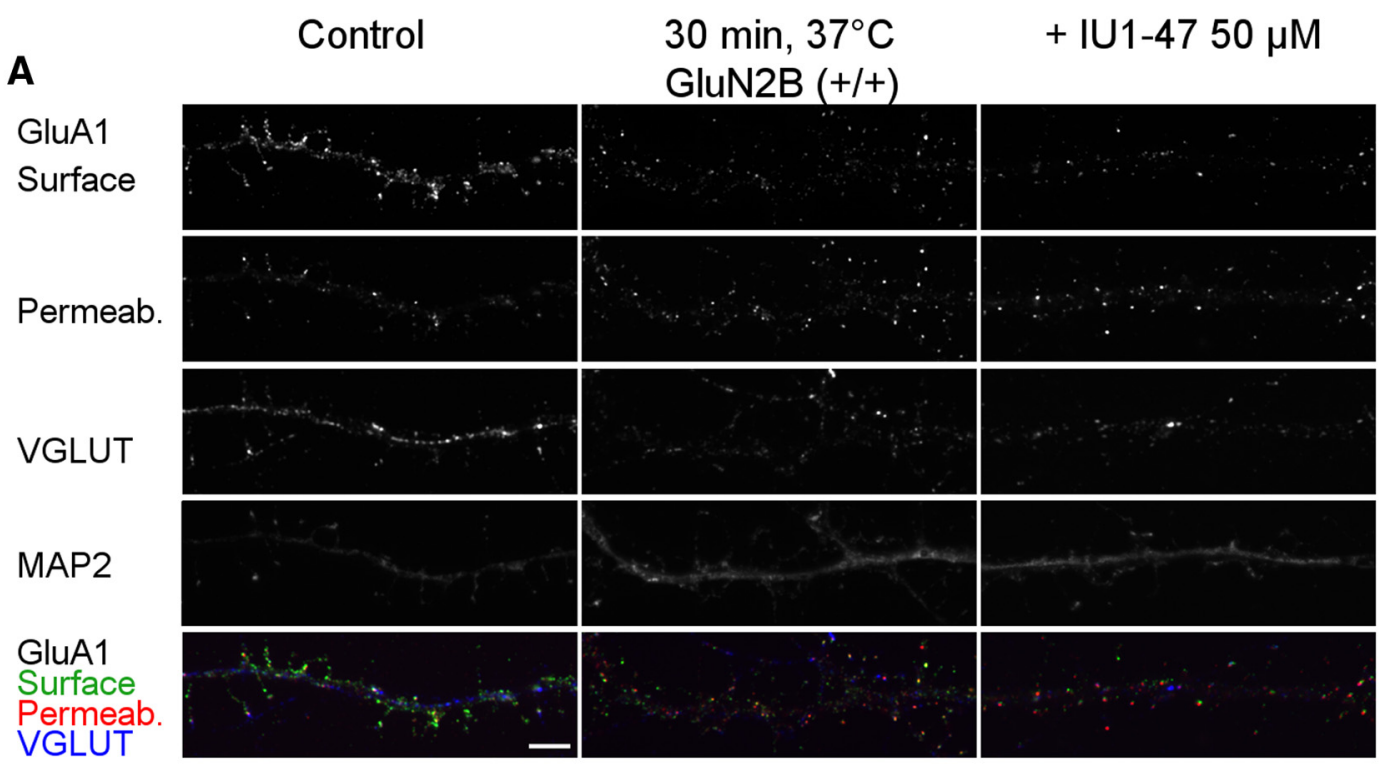

B

GluN2B (-I-)

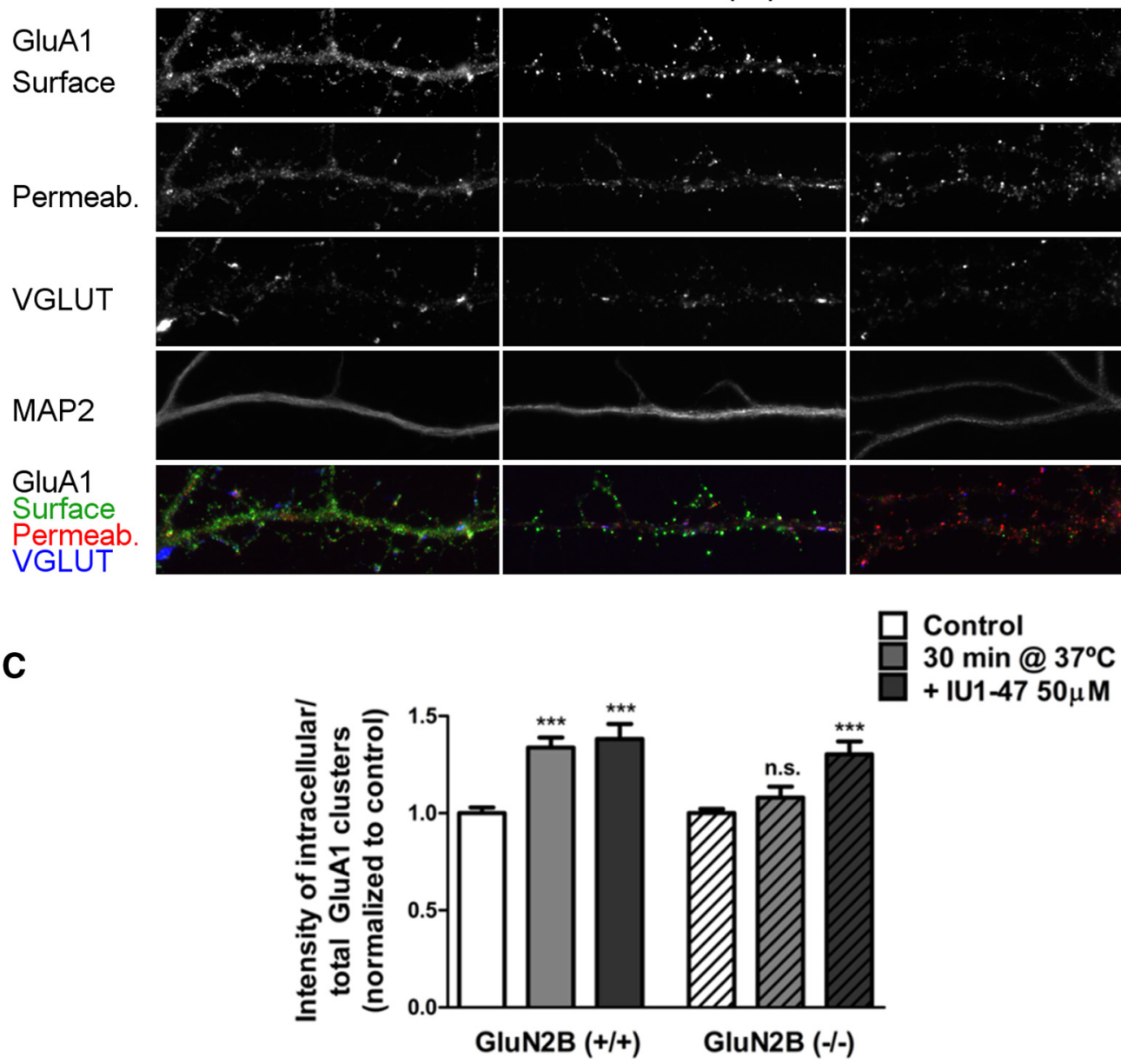

Figure 9. Activation of the proteasome partially recovers AMPAR endocytosis in GluN2B ${ }^{-1-}$ neurons. $A, B$, Low-density hippocampal cultures from wild-type and GluN2B ${ }^{+/-}(A)$ and GluN2B ${ }^{-1-}(B)$ mice were immunostained at 14 DIV for surface-GluA1 (live staining) and incubated for $0 \mathrm{~min}$ (control) or $30 \mathrm{~min}$ at $37^{\circ} \mathrm{C}$ to induce endocytosis (antibody-feeding assay). Where indicated, neurons were preincubated for $30 \mathrm{~min}$ at $37^{\circ} \mathrm{C}$ with $50 \mu \mathrm{m}$ IU1-47. Neurons were fixed and stained for the surface remaining GluA1 clusters (surface, green merge) and then permeabilized and stained for the GluA1 clusters that were internalized (permeab., red merge). VGLUT (blue merge) and MAP2 staining were used as a presynaptic and a dendritic marker, respectively. Scale bar, $5 \mu \mathrm{m}$. C, Integrated intensity of the surface and permeabilized GluA1 clusters per dendritic length was analyzed. The data are presented as the ratio of intracellular clusters (permeabilized) per total clusters (surface + permeabilized) and normalized to the respective controls. Data are presented as mean $\pm \mathrm{SEM}, n=49-50$ cells from five independent experiments. ${ }^{* * *} p<0.0001, n .5 ., p>0.05$, compared with the respective control, one-way ANOVA followed by Dunnett's multiple-comparisons test. 
rescued by reintroduction of GluN2B, but not by a mutant of GluN2B unable to bind CaMKII (Wang et al., 2011). This suggests that the preferential association of CaMKII to GluN2B is necessary for the suppression of AMPAR synaptic incorporation under basal conditions. Notably, CaMKII $\alpha$ mediates the recruitment of proteasomes to dendritic spines in an activity-dependent way (Bingol et al., 2010) and the binding of CaMKII to the GluN2B subunit of NMDARs upon $\mathrm{Ca}^{2+}$ influx is important to position CaMKII to synapses (Halt et al., 2012). The decrease in the synaptic proteasome subunit levels observed by us in the PSDs of GluN2B ${ }^{-1-}$ neurons (Table 1), together with the role of CaMKII acting as a scaffold to recruit proteasomes to dendritic spines (Bingol et al., 2010), the requirement for CaMKII binding to GluN2B to restore normal AMPAR currents (Wang et al., 2011), and the regulation of AMPAR levels and traffic by the proteasome (Patrick et al., 2003; Lussier et al., 2011), led us to raise the hypothesis that the decrease in synaptic proteasome may underlie at least partially the increase in synaptic AMPARs in the absence of GluN2B. In fact, we observed that GluA1 internalization is impaired in GluN2B ${ }^{-1-}$ neurons (Fig. 6), pointing to a disturbance in the endocytosis of AMPARs that requires the proteasome (Patrick et al., 2003). Strikingly, we could rescue synaptic AMPAR levels in GluN2B ${ }^{-1-}$ hippocampal neurons to levels similar to those observed in wild-type neurons by enhancing the proteasome activity with a small-molecule inhibitor of Usp14 (Fig. 8). Overactivation of the remaining synaptic proteasome appears to be sufficient for normal internalization of GluA1AMPARs (Fig. 9) and to restore normal synaptic AMPAR levels in GluN2B $^{-1-}$ neurons. Accordingly, a recent study showed that glutamate transporter inactivity results in elevated internalization of AMPARs, an effect that is dependent on parasynaptic GluN2B-containing NMDARs and on the proteasome (Jarzylo and Man, 2012).

GluN2B negatively regulates local translation in neurons through the activation of the mTOR signaling pathway (Wang et al., 2011). Recently, the proteasome was found to regulate protein synthesis during late-phase long-term potentiation by balancing the accumulation of translation activators or repressors (Dong et al., 2014). It is possible that the decreased proteasome synaptic levels in GluN2B ${ }^{-1-}$ mice may mediate the effect on the mTOR signaling pathway (Wang et al., 2011).

The quantitative proteomic analysis of the PSDs of GluN2B ${ }^{-1-}$ and control neurons revealed that no single protein is totally absent from the PSDs of GluN2B ${ }^{-/-}$neurons, but several proteins have altered levels that could have physiological and morphological implications (Table 1). Proteins related to the actin cytoskeleton, GTPases, cell adhesion molecules, proteins implicated in translation and protein folding, and others were found to be differentially expressed at the PSD in the absence of GluN2B. These proteins are prime candidates for the GluN2Bassembled synaptic scaffold and their synaptic roles deserve further attention.

In conclusion, our data highlight the indispensable role of the GluN2B subunit in the targeting and/or stabilization of NMDARs at the synapse and the prominent role of these receptors in limiting the synaptic content of AMPARs in basal conditions. This inhibitory mechanism is correlated with impaired AMPAR endocytosis and decreased levels of the synaptic proteasome and can be overridden by enhancing the activity of the proteasome. Our data suggest that a GluN2B-NMDAR-dependent synaptic proteasome population limits the constitutive trafficking of AMPARs eventually by promoting their endocytosis, thereby ensur- ing that synapses acquire AMPARs primarily upon strongly correlated neuronal activity.

\section{References}

Adesnik H, Li G, During MJ, Pleasure SJ, Nicoll RA (2008) NMDA receptors inhibit synapse unsilencing during brain development. Proc Natl Acad Sci U S A 105:5597-5602. CrossRef Medline

Aggarwal K, Choe LH, Lee KH (2005) Quantitative analysis of protein expression using amine-specific isobaric tags in Escherichia colicells expressing rhsA elements. Proteomics 5:2297-2308. CrossRef Medline

Akashi K, Kakizaki T, Kamiya H, Fukaya M, Yamasaki M, Abe M, Natsume R, Watanabe M, Sakimura K (2009) NMDA receptor GluN2B (GluR epsilon 2/NR2B) subunit is crucial for channel function, postsynaptic macromolecular organization, and actin cytoskeleton at hippocampal CA3 synapses. J Neurosci 29:10869-10882. CrossRef Medline

Akazawa C, Shigemoto R, Bessho Y, Nakanishi S, Mizuno N (1994) Differential expression of five $\mathrm{N}$-methyl-D-aspartate receptor subunit mRNAs in the cerebellum of developing and adult rats. J Comp Neurol 347:150 160. CrossRef Medline

Anggono V, Huganir RL (2012) Regulation of AMPA receptor trafficking and synaptic plasticity. Curr Opin Neurobiol 22:461-469. CrossRef Medline

Barria A, Malinow R (2002) Subunit-specific NMDA receptor trafficking to synapses. Neuron 35:345-353. CrossRef Medline

Bellone C, Nicoll RA (2007) Rapid bidirectional switching of synaptic NMDA receptors. Neuron 55:779-785. CrossRef Medline

Bingol B, Sheng M (2011) Deconstruction for reconstruction: the role of proteolysis in neural plasticity and disease. Neuron 69:22-32. CrossRef Medline

Bingol B, Wang CF, Arnott D, Cheng D, Peng J, Sheng M (2010) Autophosphorylated CaMKIIalpha acts as a scaffold to recruit proteasomes to dendritic spines. Cell 140:567-578. CrossRef Medline

Brigman JL, Wright T, Talani G, Prasad-Mulcare S, Jinde S, Seabold GK, Mathur P, Davis MI, Bock R, Gustin RM, Colbran RJ, Alvarez VA, Nakazawa K, Delpire E, Lovinger DM, Holmes A (2010) Loss of GluN2Bcontaining NMDA receptors in CA1 hippocampus and cortex impairs long-term depression, reduces dendritic spine density, and disrupts learning. J Neurosci 30:4590-4600. CrossRef Medline

Caldeira MV, Curcio M, Leal G, Salazar IL, Mele M, Santos AR, Melo CV, Pereira P, Canzoniero LM, Duarte CB (2013) Excitotoxic stimulation downregulates the ubiquitin-proteasome system through activation of NMDA receptors in cultured hippocampal neurons. Biochim Biophys Acta 1832:263-274. CrossRef Medline

Cheng D, Hoogenraad CC, Rush J, Ramm E, Schlager MA, Duong DM, Xu P, Wijayawardana SR, Hanfelt J, Nakagawa T, Sheng M, Peng J (2006) Relative and absolute quantification of postsynaptic density proteome isolated from rat forebrain and cerebellum. Mol Cell Proteomics 5:1158 1170. CrossRef Medline

Chung HJ, Xia J, Scannevin RH, Zhang X, Huganir RL (2000) Phosphorylation of the AMPA receptor subunit GluR2 differentially regulates its interaction with PDZ domain-containing proteins. J Neurosci 20:72587267. Medline

Colledge M, Snyder EM, Crozier RA, Soderling JA, Jin Y, Langeberg LK, Lu H, Bear MF, Scott JD (2003) Ubiquitination regulates PSD-95 degradation and AMPA receptor surface expression. Neuron 40:595-607. CrossRef Medline

Collins MO, Husi H, Yu L, Brandon JM, Anderson CN, Blackstock WP, Choudhary JS, Grant SG (2006) Molecular characterization and comparison of the components and multiprotein complexes in the postsynaptic proteome. J Neurochem 97:16-23. CrossRef Medline

Dong C, Upadhya SC, Ding L, Smith TK, Hegde AN (2008) Proteasome inhibition enhances the induction and impairs the maintenance of latephase long-term potentiation. Learn Mem 15:335-347. CrossRef Medline

Dong C, Bach SV, Haynes KA, Hegde AN (2014) Proteasome modulates positive and negative translational regulators in long-term synaptic plasticity. J Neurosci 34:3171-3182. CrossRef Medline

Dosemeci A, Makusky AJ, Jankowska-Stephens E, Yang X, Slotta DJ, Markey SP (2007) Composition of the synaptic PSD-95 complex. Mol Cell Proteomics 6:1749-1760. CrossRef Medline

Ehlers MD (2003) Activity level controls postsynaptic composition and signaling via the ubiquitin-proteasome system. Nat Neurosci 6:231-242. CrossRef Medline 
Ferreira JS, Rooyakkers A, She K, Ribeiro L, Carvalho AL, Craig AM (2011) Activity and protein kinase $\mathrm{C}$ regulate synaptic accumulation of $\mathrm{N}$-methyl-D-aspartate (NMDA) receptors independently of GluN1 splice variant. J Biol Chem 286:28331-28342. CrossRef Medline

Fonseca R, Vabulas RM, Hartl FU, Bonhoeffer T, Nägerl UV (2006) A balance of protein synthesis and proteasome-dependent degradation determines the maintenance of LTP. Neuron 52:239-245. CrossRef Medline

Furukawa H, Gouaux E (2003) Mechanisms of activation, inhibition and specificity: crystal structures of the NMDA receptor NR1 ligand-binding core. EMBO J 22:2873-2885. CrossRef Medline

Furukawa H, Singh SK, Mancusso R, Gouaux E (2005) Subunit arrangement and function in NMDA receptors. Nature 438:185-192. CrossRef Medline

Gambrill AC, Barria A (2011) NMDA receptor subunit composition controls synaptogenesis and synapse stabilization. Proc Natl Acad Sci U S A 108:5855-5860. CrossRef Medline

Gomes AR, Ferreira JS, Paternain AV, Lerma J, Duarte CB, Carvalho AL (2008) Characterization of alternatively spliced isoforms of AMPA receptor subunits encoding truncated receptors. Mol Cell Neurosci 37:323334. CrossRef Medline

Gray JA, Shi Y, Usui H, During MJ, Sakimura K, Nicoll RA (2011) Distinct modes of AMPA receptor suppression at developing synapses by GluN2A and GluN2B: single-cell NMDA receptor subunit deletion in vivo. Neuron 71:1085-1101. CrossRef Medline

Hall BJ, Ghosh A (2008) Regulation of AMPA receptor recruitment at developing synapses. Trends Neurosci 31:82-89. CrossRef Medline

Hall BJ, Ripley B, Ghosh A (2007) NR2B signaling regulates the development of synaptic AMPA receptor current. J Neurosci 27:13446-13456. CrossRef Medline

Halt AR, Dallapiazza RF, Zhou Y, Stein IS, Qian H, Juntti S, Wojcik S, Brose N, Silva AJ, Hell JW (2012) CaMKII binding to GluN2B is critical during memory consolidation. EMBO J 31:1203-1216. CrossRef Medline

Huh KH, Wenthold RJ (1999) Turnover analysis of glutamate receptors identifies a rapidly degraded pool of the N-methyl-D-aspartate receptor subunit, NR1, in cultured cerebellar granule cells. J Biol Chem 274:151157. CrossRef Medline

Husi H, Ward MA, Choudhary JS, Blackstock WP, Grant SG (2000) Proteomic analysis of NMDA receptor-adhesion protein signaling complexes. Nat Neurosci 3:661-669. CrossRef Medline

Jarzylo LA, Man HY (2012) Parasynaptic NMDA receptor signaling couples neuronal glutamate transporter function to AMPA receptor synaptic distribution and stability. J Neurosci 32:2552-2563. CrossRef Medline

Jaskolski F, Mayo-Martin B, Jane D, Henley JM (2009) Dynamindependent membrane drift recruits AMPA receptors to dendritic spines. J Biol Chem 284:12491-12503. CrossRef Medline

Kaech S, Banker G (2006) Culturing hippocampal neurons. Nat Protoc 1:2406-2415. CrossRef Medline

Kim MJ, Dunah AW, Wang YT, Sheng M (2005) Differential roles of NR2Aand NR2B-containing NMDA receptors in Ras-ERK signaling and AMPA receptor trafficking. Neuron 46:745-760. CrossRef Medline

Klemmer P, Meredith RM, Holmgren CD, Klychnikov OI, Stahl-Zeng J, Loos M, van der Schors RC, Wortel J, de Wit H, Spijker S, Rotaru DC, Mansvelder HD, Smit AB, Li KW (2011) Proteomics, ultrastructure, and physiology of hippocampal synapses in a fragile $\mathrm{X}$ syndrome mouse model reveal presynaptic phenotype. J Biol Chem 286:25495-25504. CrossRef Medline

Kutsuwada T, Sakimura K, Manabe T, Takayama C, Katakura N, Kushiya E, Natsume R, Watanabe M, Inoue Y, Yagi T, Aizawa S, Arakawa M, Takahashi T, Nakamura Y, Mori H, Mishina M (1996) Impairment of suckling response, trigeminal neuronal pattern formation, and hippocampal LTD in NMDA receptor epsilon 2 subunit mutant mice. Neuron 16:333344. CrossRef Medline

Lee BH, Lee MJ, Park S, Oh DC, Elsasser S, Chen PC, Gartner C, Dimova N, Hanna J, Gygi SP, Wilson SM, King RW, Finley D (2010) Enhancement of proteasome activity by a small-molecule inhibitor of USP14. Nature 467:179-184. CrossRef Medline

Li KW, Miller S, Klychnikov O, Loos M, Stahl-Zeng J, Spijker S, Mayford M, Smit AB (2007) Quantitative proteomics and protein network analysis of hippocampal synapses of CaMKIIalpha mutant mice. J Proteome Res 6:3127-3133. CrossRef Medline

Lin JW, Ju W, Foster K, Lee SH, Ahmadian G, Wyszynski M, Wang YT, Sheng M (2000) Distinct molecular mechanisms and divergent endocytotic pathways of AMPA receptor internalization. Nat Neurosci 3:1282-1290. CrossRef Medline

Liu Y, Wong TP, Aarts M, Rooyakkers A, Liu L, Lai TW, Wu DC, Lu J, Tymianski M, Craig AM, Wang YT (2007) NMDA receptor subunits have differential roles in mediating excitotoxic neuronal death both in vitro and in vivo. J Neurosci 27:2846-2857. CrossRef Medline

Louros SR, Hooks BM, Litvina L, Carvalho AL, Chen C (2014) A role for stargazin in experience-dependent plasticity. Cell Rep 7:1614-1625. CrossRef Medline

Lu W, Gray JA, Granger AJ, During MJ, Nicoll RA (2011) Potentiation of synaptic AMPA receptors induced by the deletion of NMDA receptors requires the GluA2 subunit. J Neurophysiol 105:923-928. CrossRef Medline

Lussier MP, Nasu-Nishimura Y, Roche KW (2011) Activity-dependent ubiquitination of the AMPA receptor subunit GluA2. J Neurosci 31:30773081. CrossRef Medline

Manadas B, Santos AR, Szabadfi K, Gomes JR, Garbis SD, Fountoulakis M, Duarte CB (2009) BDNF-induced changes in the expression of the translation machinery in hippocampal neurons: protein levels and dendritic mRNA. J Proteome Res 8:4536-4552. CrossRef Medline

Matsuda S, Mikawa S, Hirai H (1999) Phosphorylation of serine-880 in GluR2 by protein kinase $\mathrm{C}$ prevents its $\mathrm{C}$ terminus from binding with glutamate receptor-interacting protein. J Neurochem 73:1765-1768. Medline

Mayer ML, Westbrook GL, Guthrie PB (1984) Voltage-dependent block by $\mathrm{Mg} 2+$ of NMDA responses in spinal cord neurones. Nature 309:261-263. CrossRef Medline

Monyer H, Sprengel R, Schoepfer R, Herb A, Higuchi M, Lomeli H, Burnashev N, Sakmann B, Seeburg PH (1992) Heteromeric NMDA receptors: molecular and functional distinction of subtypes. Science 256:1217-1221. CrossRef Medline

Monyer H, Burnashev N, Laurie DJ, Sakmann B, Seeburg PH (1994) Developmental and regional expression in the rat brain and functional properties of four NMDA receptors. Neuron 12:529-540. CrossRef Medline

Opazo P, Labrecque S, Tigaret CM, Frouin A, Wiseman PW, De Koninck P, Choquet D (2010) CaMKII triggers the diffusional trapping of surface AMPARs through phosphorylation of stargazin. Neuron 67:239-252. CrossRef Medline

Paoletti P, Bellone C, Zhou Q (2013) NMDA receptor subunit diversity: impact on receptor properties, synaptic plasticity and disease. Nat Rev Neurosci 14:383-400. CrossRef Medline

Patrick GN, Bingol B, Weld HA, Schuman EM (2003) Ubiquitin-mediated proteasome activity is required for agonist-induced endocytosis of GluRs. Curr Biol 13:2073-2081. CrossRef Medline

Peca J, Feliciano C, Ting JT, Wang W, Wells MF, Venkatraman TN, Lascola CD, Fu Z, Feng G (2011) Shank3 mutant mice display autistic-like behaviours and striatal dysfunction. Nature 472:437-442. CrossRef Medline

Quinlan EM, Philpot BD, Huganir RL, Bear MF (1999) Rapid, experiencedependent expression of synaptic NMDA receptors in visual cortex in vivo. Nat Neurosci 2:352-357. CrossRef Medline

Rao A, Craig AM (1997) Activity regulates the synaptic localization of the NMDA receptor in hippocampal neurons. Neuron 19:801-812. CrossRef Medline

Rao A, Kim E, Sheng M, Craig AM (1998) Heterogeneity in the molecular composition of excitatory postsynaptic sites during development of hippocampal neurons in culture. J Neurosci 18:1217-1229. Medline

Rumbaugh G, Adams JP, Kim JH, Huganir RL (2006) SynGAP regulates synaptic strength and mitogen-activated protein kinases in cultured neurons. Proc Natl Acad Sci U S A 103:4344-4351. CrossRef Medline

Santos AR, Mele M, Vaz SH, Kellermayer B, Grimaldi M, Colino-Oliveira M, Rombo DM, Comprido D, Sebastião AM, Duarte CB (2015) Differential role of the proteasome in the early and late phases of BDNFinduced facilitation of LTP. J Neurosci 35:3319-3329. CrossRef Medline

Santos SD, Carvalho AL, Caldeira MV, Duarte CB (2009) Regulation of AMPA receptors and synaptic plasticity. Neuroscience 158:105-125. CrossRef Medline

Sheng M, Hoogenraad CC (2007) The postsynaptic architecture of excitatory synapses: a more quantitative view. Annu Rev Biochem 76:823-847. CrossRef Medline

Sheng M, Cummings J, Roldan LA, Jan YN, Jan LY (1994) Changing sub- 
unit composition of heteromeric NMDA receptors during development of rat cortex. Nature 368:144-147. CrossRef Medline

Tasaki T, Mulder LC, Iwamatsu A, Lee MJ, Davydov IV, Varshavsky A, Muesing M, Kwon YT (2005) A family of mammalian E3 ubiquitin ligases that contain the UBR box motif and recognize N-degrons. Mol Cell Biol 25:7120-7136. CrossRef Medline

Tomita S, Chen L, Kawasaki Y, Petralia RS, Wenthold RJ, Nicoll RA, Bredt DS (2003) Functional studies and distribution define a family of transmembrane AMPA receptor regulatory proteins. J Cell Biol 161:805-816. CrossRef Medline

Tovar KR, Sprouffske K, Westbrook GL (2000) Fast NMDA receptormediated synaptic currents in neurons from mice lacking the epsilon2 (NR2B) subunit. J Neurophysiol 83:616-620. Medline

Turrigiano GG, Leslie KR, Desai NS, Rutherford LC, Nelson SB (1998) Activity-dependent scaling of quantal amplitude in neocortical neurons. Nature 391:892-896. CrossRef Medline

Ulbrich MH, Isacoff EY (2008) Rules of engagement for NMDA receptor subunits. Proc Natl Acad Sci U S A 105:14163-14168. CrossRef Medline

Ultanir SK, Kim JE, Hall BJ, Deerinck T, Ellisman M, Ghosh A (2007) Regulation of spine morphology and spine density by NMDA receptor signaling in vivo. Proc Natl Acad Sci U S A 104:19553-19558. CrossRef Medline

von Engelhardt J, Doganci B, Jensen V, Hvalby Ø, Göngrich C, Taylor A, Barkus C, Sanderson DJ, Rawlins JN, Seeburg PH, Bannerman DM, Monyer H (2008) Contribution of hippocampal and extra-hippocampal NR2B-containing
NMDA receptors to performance on spatial learning tasks. Neuron 60:846-860. CrossRef Medline

Wang CC, Held RG, Chang SC, Yang L, Delpire E, Ghosh A, Hall BJ (2011) A critical role for GluN2B-containing NMDA receptors in cortical development and function. Neuron 72:789-805. CrossRef Medline

Wang CC, Held RG, Hall BJ (2013) SynGAP regulates protein synthesis and homeostatic synaptic plasticity in developing cortical networks. PLoS One 8:e83941. CrossRef Medline

Watanabe M, Inoue Y, Sakimura K, Mishina M (1992) Developmental changes in distribution of NMDA receptor channel subunit mRNAs. Neuroreport 3:1138-1140. CrossRef Medline

Yashiro K, Philpot BD (2008) Regulation of NMDA receptor subunit expression and its implications for LTD, LTP, and metaplasticity. Neuropharmacology 55:1081-1094. CrossRef Medline

Zeeberg BR, Feng W, Wang G, Wang MD, Fojo AT, Sunshine M, Narasimhan S, Kane DW, Reinhold WC, Lababidi S, Bussey KJ, Riss J, Barrett JC, Weinstein JN (2003) GoMiner: a resource for biological interpretation of genomic and proteomic data. Genome Biol 4:R28. CrossRef Medline

Zhang G, Neubert TA, Jordan BA (2012) RNA binding proteins accumulate at the postsynaptic density with synaptic activity. J Neurosci 32:599-609. CrossRef Medline

Zhang W, Benson DL (2001) Stages of synapse development defined by dependence on F-actin. J Neurosci 21:5169-5181. Medline 